\title{
1 Dissecting the structural and functional roles of a vicinal iron- 2 binding site in encapsulated ferritins
}

3

4

5

6

7

8

Cecilia Piergentili ${ }^{1, *}$, Jennifer Ross ${ }^{2, *}$, Didi He ${ }^{3, \#, *}$, Kelly J. Gallagher ${ }^{2}$, Will A. Stanley ${ }^{1}$, Laurène Adam $^{1}$, C. Logan Mackay ${ }^{2}$, Kevin J. Waldron ${ }^{4}$, David J. Clarke ${ }^{2 *}$, Jon Marles-Wright $^{1^{*}}$

${ }^{1}$ School of Natural and Environmental Sciences, Newcastle University. Newcastle upon Tyne, NE1 7RU; ${ }^{2}$ EaStCHEM School of Chemistry, The University of Edinburgh, Joseph Black Building,

David Brewster Road, Edinburgh, Scotland, EH9 3FJ; ${ }^{3}$ Institute of Quantitative Biology, Biochemistry and Biotechnology, School of Biological Sciences, The University of Edinburgh, Max Born Crescent, Edinburgh, EH9 3BF; ${ }^{4}$ Biosciences Institute, Newcastle University, Newcastle upon Tyne, NE2 4HH.

${ }^{\#}$ Current address: Structural Genomics Consortium, University of Oxford, Old Road Campus Research Building, Roosvelt Drive, Oxford, OX3 $7 D Q$

* These authors contributed equally to this work

* Corresponding authors

Contact details:

Email:Dave.clarke@ed.ac.uk

Tel: +44(0)1316504808

Email: Jon.marles-wright1@ @ ncl.ac.uk

Tel: +44(0)1912084855 


\section{Abstract}

Encapsulated ferritins belong to the universally distributed ferritin superfamily, which function as iron detoxification and storage systems. Encapsulated ferritins have a distinct annular structure and must associate with an encapsulin nanocage to form a competent iron store that is capable of holding significantly more iron than classical ferritins. The catalytic mechanism of iron oxidation in the ferritin family is still an open question, due to differences in organization of the ferroxidase catalytic site and secondary metal binding sites vicinal to this. We have previously identified a metal binding site on the inner surface of the Rhodospirillum rubrum encapsulated ferritin at the interface between the two-helix subunits and proximal to the ferroxidase center. Here we present a comprehensive structural and functional study to investigate the functional relevance of this proposed iron entry site by means of enzymatic assays, mass-spectrometry, and X-ray crystallography. We show that catalysis occurs in the ferroxidase center and suggest a dual role for the secondary site, which both serves to attract metal ions to the ferroxidase center and acts as a flow-restricting valve to limit the activity of the ferroxidase center. Moreover, confinement of encapsulated ferritins within the encapsulin nanocage, while enhancing the ability of the encapsulated ferritin to undergo catalysis, does not influence the function of the secondary site. 


\section{Introduction}

47 The ferritin superfamily consists of a number of structurally and functionally distinct members, each of which is built around a four-helix bundle scaffold for an iron-binding di-iron ferroxidase active site (Andrews, 2010). The quaternary structure of these protein families shows a high degree

of variation: from monomeric rubrerythrin proteins (Cardenas et al., 2016; Dillard et al., 2011);

dimeric iron-mineralizing encapsulin-associated firmicute (IMEF) proteins (Giessen et al., 2019);

Kolter, 1997; Pesek et al., 2011); the 24-meric classical ferritins (Ftn) and bacterioferritins (Bfr)

(Andrews, 1998; Frolow et al., 1994; Harrison and Arosio, 1996; Pfaffen et al., 2013); and the decameric encapsulated ferritins (EncFtn) (He et al., 2019, 2016). The rubrerythrin and DPS proteins play key roles in the protection of cells from oxidative stress, while DPS and the other members of the ferritin superfamily are vital iron stores (Almiron et al., 1992; Chiancone and Ceci, 2010; Choi et al., 2000; De Martino et al., 2016; Martinez and Kolter, 1997; Nair and Finkel, 2004;

Ratnayake et al., 2000; Sztukowska et al., 2002). These latter proteins oxidize and convert free $\mathrm{Fe}(\mathrm{II})$ to inert $\mathrm{Fe}$ (III) oxyhydroxide or $\mathrm{Fe}(\mathrm{III})$ phosphate mineral forms that provide a reservoir of bioavailable iron (Chasteen and Harrison, 1999). The nanocages formed by the quaternary structure of DPS, Ftn, and Bfr allow iron oxidation and mineralization to occur within a biochemically privileged environment within the cell, which protects the host cell from iron-induced oxidative stress. Interestingly, the recently described IMEF and EncFtn proteins both have ferroxidase activity, but they do not form nanocage structures on their own, instead they must be localized to the lumen of encapsulin nanocages to form a competent iron-store (Giessen et al., 2019; He et al., 2019, 2016). EncFtn and IMEF are directed into encapsulins by a terminal localization sequence that binds to the interior wall of encapsulin. The EncFtn proteins form a distinct homodecameric annular assembly, with a pentamer of dimers topology (Figure 1A). One of the dimer interfaces 
71 which reconstitute a unique symmetrical ferroxidase center across a dimer interface when iron is

72 bound (Figure 1C) (Ross et al., 2020).

73

74 The catalytic route to iron mineralization in the different ferritin iron-stores is still a subject of 75 vigorous debate (Baaghil et al., 2003; Chasteen and Harrison, 1999; Ebrahimi et al., 2009; Proulx76 Curry and Chasteen, 1995; Xu and Chasteen, 1991; Yang et al., 1998). Given the lack of absolute 77 conservation in structure of the ferroxidase center, it is likely that there is no single conserved 78 mechanism for their activity (Baaghil et al., 2003; Chasteen and Harrison, 1999; Ebrahimi et al., 79 2009; Proulx-Curry and Chasteen, 1995; Xu and Chasteen, 1991; Yang et al., 1998). All of the 80 ferritin family proteins that have been structurally characterized have additional iron-binding sites 81 proximal to the ferroxidase center. In the case of the sites proximal to the ferroxidase center 82 identified in DPS and ferritins, these have been suggested to be iron-entry, transit, and exit points 83 from the ferroxidase center (Behera et al., 2015; Masuda et al., 2010; Theil et al., 2013), or the sites 84 of electron transfer from Fe(II) substrates to the FOC (Yao et al., 2012). The subunit boundaries in 85 the DPS and ferritin nanocages form a variety of symmetrical pores, which have variously been 86 suggested or shown to be entry and exit sites to the lumen for iron, water and phosphate substrates 87 (Andrews, 1998; Bellapadrona et al., 2009; Giessen et al., 2019; Liu et al., 2007; Treffry and Harrison, 1978). Whatever their function, these secondary metal sites are essential to the correct functioning of the ferritin iron-stores (Ebrahimi et al., 2016; W. Hagen et al., 2017; Treffry et al., 1998).

In our previous work on the EncFtn family we identified a number of conserved secondary metal-

93 binding sites (He et al., 2019, 2016). A partially occupied metal ion site was present on the outer 94 surface (proposed exit site) of the EncFtn decamer (Figure 1A in (He et al., 2016)), and a highly 95 occupied metal ion site was present on the inner face (proposed entry site), which is proximal to the 96 ferroxidase center (Figure 1B in (He et al., 2016) (Figure 2A and B). Both of these sites are found at 
dimer interfaces between the two-helix EncFtn subunits and are formed when the four-helical ferritin fold is reconstituted by the iron-mediated assembly of the EncFtn ferroxidase center (Ross et al., 2020). A comparison of these sites to secondary metal binding sites in other ferritin family members highlights the fact that ' $\mathrm{C}$ ' site, first identified in the E. coli ferritin (Hempstead et al., 1994; Stillman et al., 2001), is topologically similar to the proposed iron-exit site identified in our previous work, whereas the entry site is unique to the EncFtn family (He et al., 2016). In our structure of the $R$. rubrum EncFtn protein, the entry site coordinates a calcium ion from the crystallization solution in a symmetrical arrangement of glutamic acid residues (E31/E34) and a tryptophan residue (W38) contributed by each chain from the ferroxidase center dimer (Ross et al., 2020) (Figure 2C). The metal coordination distances between the side chain carboxylic acid oxygens and calcium ion are $2.1 \AA \mathrm{Ca}-\mathrm{Glu} 31-\mathrm{Ox}, 2.7 \AA \mathrm{Glu} 34-\mathrm{Ox}$, which are similar to the Fe Glu - Ox coordination distances seen in the FOC of 2.2-2.6.

We hypothesize that this site acts as an entry site for iron ions approaching the ferroxidase center, and acts in some way to control the access of metal ions to the active site of the protein (Figure 2D). The glutamic acid residues in the entry site are arranged in such a way as to capture and coordinate an Fe(II) ion in an octahedral geometry before passing it to the FOC. The positioning of W38 adjacent to this site suggests that the indole ring sterically constrains the position of the E31 side chain to an optimal position for metal coordination. We have considered several hypotheses regarding the functional role of the entry site, including acting as a flow restrictor valve to limit the flow of metal ions to the FOC ("valve" function); an electrostatic funnel to direct metal ions to the FOC ("attraction" function); a discriminatory filter to avoid mis-metalation and consequent inhibition of the active site ("filter" function) (Figure $2 \mathrm{E} / \mathrm{F} / \mathrm{G}$ ); or for protein stability and assembly ("stabilizing" function). It is also possible that these functions may overlap, and the entry site may play a number of key roles in the stability and activity of the encapsulated ferritins. 
123 In order to understand the role of the entry site, a number of single-point variants of the R. rubrum

124 EncFtn protein were produced by site-directed mutagenesis of heterologous expression plasmids to

125 replace the residue of interest with non-metal binding residues. These variants were produced in the

126 isolated R. rubrum EncFtn protein alone and in an R. rubrum Encapsulin:EncFtn (Enc:EncFtn) co-

127 expression system. We produced and purified recombinant E31A, E34A and W38G/A variants of

128 EncFtn and the Enc:EncFtn complex and analyzed the solution and gas phase behavior of these

129 proteins to understand the influence of these variants on the stability of the EncFtn complex. We

130 obtained X-ray crystal structures of the E31A and E34A variants of the EncFtn protein, finding that

131 their structures display altered entry site geometry, with the abrogation of metal binding in this site

132 in the E34A variant. The functional role of the entry site was explored biochemically; we show that

133 changes of metal coordination in this site enhance the ferroxidase activity of the EncFtn protein,

134 while increasing its susceptibility to inhibition by competing zinc ions. Taken together, these results

135 indicate that the entry site plays a minor role in stabilizing the oligomeric state of the EncFtn

136 decamer, and has a dual role as a site of metal ion attraction and as a flow restrictor valve to limit

137 metal access to the ferroxidase center and thus slow the oxidation of ferrous ions to ferric ions. 


\section{Results}

\section{Purification of variant encapsulated ferritins}

140 In order to explore the functional roles of the residues in the entry site of the R. rubrum EncFtn, a 141 number of single point variants were produced by site-directed mutagenesis, removing each metal

142 binding residue in turn and substituting each with alanine or glycine. The resulting set of variants

143 were also generated in association with the encapsulin (Enc) to produce Enc:EncFtn complexes. All 144 proteins were produced by heterologous expression in Escherichia coli.

146 Our previous work demonstrated that changes to the ferroxidase center affect both the assembly and 147 activity of the $R$. rubrum EncFtn (EncFtn-WT) (He et al., 2016). To investigate whether changes to 148 the entry site influence the quaternary structure of the EncFtn protein, each variant was subjected to 149 size-exclusion chromatography using a HiLoad 16/60 Superdex 200 (S200) column calibrated with 150 standards of known molecular mass (Figure 3A and B). The average molecular masses of the 151 EncFtn proteins were confirmed by liquid chromatography-mass spectrometry (LC-MS, Table 1). 152 Each of the variant EncFtn proteins eluted with a similar profile, with a major peak at $60 \mathrm{ml}$ 153 retention volume, a second peak at $75 \mathrm{ml}$, and the final peak at $82 \mathrm{ml}$ (Figure 3A, Figure 6-figure 154 supplement $1 \mathrm{~A}$, Table 2). The E34A variant had significantly more protein in the $82 \mathrm{ml}$ peak when 155 compared to the EncFtn-WT and E31A variant, suggesting that this change affects the stability of 156 the protein complex. Based on our prior work on the assembly pathway of the Haliangium 157 ochraceum EncFtn protein (Ross et al., 2020) and native mass spectrometry of other representative 158 members of the EncFtn family (He et al., 2019) these peaks would correspond to decamer, tetramer, 159 and dimer species, respectively. The anomalous size estimation based on calibration standards can 160 be attributed to the fact that the EncFtn proteins used in this study were full length proteins 161 complete with their flexible encapsulation sequence, which would increase the hydrodynamic 162 radius of the oligomers considerably. 
164 In contrast to the EncFtn variants, the Enc:EncFtn protein complexes all eluted as a single peak

165 within the void volume of the S200 column, indicating the formation of protein complexes larger

166 than $600,000 \mathrm{Da}$ (separation range $\mathrm{M}_{\mathrm{r}}$ for this column is $10,000-600,000 \mathrm{Da}$ ), hence not able to

167 enter the matrix pores (Figure 3B, Figure 3-figure supplement 3B, Table 2). SDS-PAGE analysis of

168 peak fractions confirmed the presence of both the EncFtn and encapsulin proteins (Figure 3-figure

169 supplement 1). To determine if these complexes had formed correctly assembled encapsulin

170 nanocages, we performed transmission electron microscopy on uranyl acetate-stained samples

171 (Figure 3-figure supplement 2, Figure 3-figure supplement 3D/E). The encapsulins purified with

172 wild type and variant EncFtn all showed characteristic $25 \mathrm{~nm}$ encapsulin cages, with visible internal

173 density for the EncFtn proteins. This is consistent with our previous observations for the

174 Enc:EncFtn wild-type complex (He et al., 2016).

177 Given the observation that the E31A and E34A EncFtn variants do not display any significant

178 differences in terms of oligomeric state and stability in solution, we subjected truncated variants of

179 these proteins with the encapsulation sequence removed and a C-terminal hexa-histidine (EncFtn-

$180 \mathrm{sH})$ to crystallization screening to determine any changes at the metal binding sites. We obtained

181 crystals of both the E31A and E34A variants in similar conditions to EncFtn-WT. We were unable

182 to obtain crystals of either W38G or W38A variants of the EncFtn protein, suggesting that

183 removing this tryptophan destabilizes the quaternary structure of the protein sufficiently to present a

184 barrier to crystallization.

185

The structures of the R. rubrum EncFtn-sH E31A and E34A variants were determined by X-ray

187 crystallography to 2.66 and $2.19 \AA$ resolution respectively. They adopt the same overall quaternary

188 fold as EncFtn-WT, with root-mean-square deviation (RMSD) C $\alpha$ differences of $0.2 \mathrm{~A}^{2}$ over $91 \mathrm{C} \alpha$

189 and $0.17 \AA^{2}$ over $90 \mathrm{C} \alpha$ for the E31A and E34A variants respectively, and an RMSD C $\alpha$ of $0.23 \AA^{2}$ 
over $90 \mathrm{C} \alpha$ between the two variants. This indicates that these amino acid substitutions do not

191 significantly alter the structure of the polypeptide backbone $\mathrm{n}$ the E31A and E34A variants. The

192 position of side chains in the FOC and their metal coordination geometry are conserved for both

193 variants, indicating that changes to the entry site do not fundamentally change the structure of the

194 FOC.

195

196 The entry site of the E31A variant appears to coordinate a metal ion via the Glu34 side chain.

197 Inspection of anomalous maps allowed us to assign this as a calcium ion; however, the coordination

198 distances are much longer than in EncFtn-WT, at $3.8 \AA$ compared to $2.8 \AA$ (Figure 4, Figure 4

199 figure supplement 1). Loss of the coordinating Glu31 side chain ligand does not appear to cause

200 gross structural rearrangements in this site, and the change in metal ion binding when compared to

201 the Wt protein can be ascribed to the change in the coordination environment around this site. In

202 contrast, the entry site of the E34A variant does not appear to coordinate any metal ions and the side

203 chain of Glu31 is flipped away by $120^{\circ}$ from this site towards Arg42 (Figure 4, Figure 4 figure

204 supplement 2), and the Trp38 indole ring is also moved away from this site when compared to

205 EncFtn-WT. Together, these local structural changes imparted by the E31A substitution greatly

206 disrupt the metal coordination in this site when compated to the WT protein.

Native mass spectrometry of EncFtn variants

209 To build on the crystal structures of the EncFtn variants, we next used native mass spectrometry to

210 study their structural dynamics and conformational heterogeneity(Ross et al., 2020). In our initial

211 studies we found that EncFtn-W38A was not amenable to native mass spectrometry analysis;

212 consequently, native MS was performed on EncFtn-WT, EncFtn-E31A, EncFtn-E34A, and EncFtn-

213 W38G.

214 
215 To interrogate the stability and oligomeric states of the EncFtn variants, we performed native MS 216 and ion mobility MS experiments on samples purified by size-exclusion chromatography (Figure 5) 217 (He et al., 2019). In native MS analysis, EncFtn-E31A behaves similarly to EncFtn-WT and 218 presents solely as a decameric charge state distribution centered around the $25+$ charge state (Figure 219 5, pink triangles). In contrast, under the same instrumental conditions, EncFtn-E34A and EncFtn220 W38G displayed both decameric and monomeric charge state distributions (Figure 5, highlighted 221 with pink triangles and blue circles, respectively). The presence of monomeric high charge states 222 (8+ to 16+ for EncFtn-E34A, and 8+ to 15+ for EncFtn-W38G) suggests a degree of gas phase 223 dissociation of the decameric complex during native MS analysis. Even with careful control of 224 instrument conditions, this monomeric dissociation product could not be completely eliminated, 225 suggesting that complexes of the EncFtn-E34A and EncFtn-W38G are less stable than EncFtn-WT. 226 Thus, these initial observations suggest that loss of either E34 or W38 results in gas phase 227 destabilization of the decamer assembly, although we cannot rule out the observed difference in 228 stability being due to different iron content within the FOC in each of these protein preparations. 229 We also note that the decameric charge state distributions of EncFtn-WT, EncFtn-E34A and 230 EncFtn-W38G are extended and include several additional higher charge, low abundance charge 231 states (Figure 5, highlighted with *) when compared to our previous EncFtn native MS analysis of a 232 truncated EncFtn-WT protein (He et al., 2016). We attribute their presence to the ability of the 233 solvent-exposed encapsulation sequence to readily protonate in solution. The difference in gas 234 phase stability of the EncFtn variants was also evident when increasing the sampling cone voltage 235 and/or activating the trap voltage of the mass spectrometer, which activates the complex and causes 236 dissociation (Figure 5-figure supplement 1). EncFtn-W38G fully dissociates into its monomer 237 charge state distribution at lower activation conditions than the other variants, further highlighting 238 the instability of its decamer form (Figure 5-figure supplement 1D). The EncFtn-E31A, EncFtn239 E34A and EncFtn-W38G variants (Figure 5-figure supplement 1, B, C and D) dissociate solely into 240 their monomer charge state distribution with higher activation conditions, whereas a dimer species 
241 is also observed for EncFtn-WT; an observation which may indicate a weakened dimer interface in

242 the variants.

244 To further investigate the gas phase structure and stability of the variants, ion mobility collision 245 induced unfolding (CIU) experiments were performed (Eschweiler et al., 2015). Each gas phase 246 decamer protein complex was activated in a stepwise manner by incremental changes of the trap 247 voltage prior to analysis of the conformation of the native protein ions using ion mobility mass 248 spectrometry. The resulting ion mobility profile (arrival time distributions) for an individual protein 249 ion is then plotted as a function of activation voltage to produce a heat map to reveal discrete 250 conformations and gas phase unfolding transitions (Figure 5-figure supplement 2). It is clear from 251 these experiments that two discrete conformations of each EncFtn variant are observed during CIU; 252 a major conformation with a compact structure and a minor conformation with a more extended, 253 unfolded structure (Figure 5-figure supplement 2 labelled ' $C$ ' and ' $E$ ' respectively, and Figure 5254 figure supplement 3). At minimal activation, EncFtn-WT, EncFtn-E34A and EncFtn-E31A all exist 255 in a single, compact decameric conformation with a drift time of between 10 and 11 ms, suggesting 256 the same overall structure. As activation is increased, all three variants undergo a discrete transition 257 to a more extended conformation (characterized by a drift time of $12.5 \mathrm{~ms}$ ) at around $30 \mathrm{~V}$ 258 activation, followed by a more complex transition to higher drift time conformations with activation 259 above approximately $40 \mathrm{~V}$, before dissociation of the complex to release monomeric subunits. The 260 close similarity of these CIU profiles strongly suggests similar gas phase structures and stability for 261 the EncFtn-WT and the E31A and E34A variants (Figure 5-figure supplement 2 and Figure 5-figure 262 supplement 3). In contrast, EncFtn-W38G occurs in the more extended conformation (12.5 ms) 263 throughout the CIU experiment (Figure 5-figure supplement 2, W38G 'E'), with the compact 264 conformation only observed as a minor species at low activations. This is in accord with the native 265 MS studies and suggests that although the W38G assembly shares similar overall structure to the 266 WT and glutamate variants, the tryptophan substitution has a significant destabilizing effect on the 
267 decameric assembly. This increased structural/conformational heterogeneity in the tryptophan

268 variant of EncFtn may account for our inability to obtain crystals in standard crystal screens.

270 By calibration of the ion mobility data, the collision cross sections (CCS) of both the discrete and 271 extended conformations of the EncFtn variant decamers were determined (Table 3). The compact 272 conformation of EncFtn-WT has a CCS of $71.40 \mathrm{~nm}^{2}$, whereas the more extended conformation, 273 observed at higher activation, has a CCS of $80.62 \mathrm{~nm}^{2}$ (Table 3). We note that the CCS of the 274 compact conformer is significantly larger than the CCS calculated from the EncFtn-sHis in the 275 crystal structure of $58.7 \mathrm{~nm}^{2}$, and the $58.2 \mathrm{~nm}^{2}$ CCS observed in previously reported IM-MS 276 experiments (He et al., 2016). However, prior studies were performed on truncated EncFtn-WT 277 protein, which has the C-terminal encapsulation sequence removed. The higher observed CCS for 278 EncFtn-WT suggests that the encapsulation sequence is on the surface of the decamer as it has an 279 increased cross-sectional area. This is in accord with our observations in the size-exclusion 280 experiments, where the EncFtn variants eluted with an apparently higher hydrodynamic radius than 281 the expected oligomeric states. Thus, apart from the significant destabilization effect on higher 282 order complex formation imparted by the tryptophan substitution, native MS and IM-MS 283 experiments suggest that there is little overall structural change between the variants and EncFtn284 WT.

\section{Ferroxidase activity of EncFtn variants}

287 The changes in metal ion coordination observed in the entry sites in the crystal structures of the 288 E31A and E34A variants suggest that these residues play a direct role in controlling the 289 accessibility of the ferroxidase center to metal ions. To test our hypotheses about the functional role 290 of this site (Figure 2), we investigated the ferroxidase activity of all of the EncFtn variants 291 produced, both in isolation, and in complex with the encapsulin protein. 
293

294 previously determined for the EncFtn-strepII variant (He et al., 2019). Surprisingly, all three 295 variants displayed higher catalytic activity than the wild-type protein (Figure 6). The EncFtn-E34A 296 variant had a 2-fold higher activity, while both the W38A and E31A mutations oxidize Fe(II) to $297 \mathrm{Fe}(\mathrm{III})$ around 5-fold faster, and their progress curves present a distinct shape in contrast to the 298 wild-type protein (Figure 6). In order to test the contribution of $\operatorname{Trp} 38$ to the encapsulated ferritin 299 catalytic activity we tested the W38A variant, allowing for a direct comparison with the other 300 variants. We also verified that the W38G and W38A variants had comparable activities in complex 301 with the Encapsulin protein (Figure 3-figure supplement 3C).

302

303

314 The crystal structure of the EncFtn-E34A variant shows that the mutation of Glu34 to Ala results in 315

The increase in activity observed by all of these variants suggest that the entry site plays a role in restricting the flow of substrate Fe(II) ions to the catalytic FOC. This is supported by the structural data available for the E31A and E34A variants. When the differences in enzymatic activity are considered in the context of the X-ray crystal structures, it is clear that the disruption of metal coordination in the entry site has a significant impact on the catalytic activity of the EncFtn protein. The EncFtn-E31A structure shows that, as a consequence of changes in metal ion coordination, the restriction in metal ion flow provided by this variant is partially removed when compared to EncFtn-WT. However, the residual glutamic acid, Glu34, is still able to coordinate metal ions, albeit less closely than the wild type enzyme, given the increased distance between these residues and lack of additional coordination from Glu31 (Figure 4).

15 a reorganization of the entry site, with the side chain of Glu31 reoriented in such a way that it is no longer correctly positioned for metal coordination, essentially removing both the electrostatic attraction and flow restriction for this site (Figure 4). A ferroxidase assay carried out with an EncFtn-E31A/E34A variant shows that its activity is comparable to EncFtn-E34A (Figure 6-figure 
supplement 3). These data corroborate our hypothesis that in EncFtn-E34A, the flow restricting function is completely abolished, and no attraction is conveyed by the residual Glu31. As no flow restriction is provided at this level, we would expect to observe a higher activity, however the

322 restructuring of this site results in a loss of any attracting forces, and consequently only a modest 323 increase in activity is observed when compared to EncFtn-WT. The difference in activity between 324 EncFtn-E31A and EncFtn-E34A shows how critical Glu34 is, and more broadly the importance of 325 this electrostatic attraction, for the activity of the protein.

As we were unable to produce crystals of the W38A variant, we could not determine the effect of removing this tryptophan residue on the structure of the entry site. However, analysis of the crystal structure of the EncFtn-WT shows that this tryptophan's indole ring appears to sterically constrain the Glu31 side chain in the correct position for metal-coordination (Figure 1, (He et al., 2016). We 331 propose that the removal of Trp38 results in the Glu31 side chain being able to move away from 332 this site. Our ferroxidase assay data show this variant as having a comparable activity profile to the 333 E31A variant; we therefore propose that the two variants possess similar entry site structures. The 334 broader destabilizing effects of the loss of the tryptophan side chain are harder to model, but the 335 loss of a side chain of the size of the tryptophan indole may lead to further structural 336 rearrangements around the internal dimer interfaces engaged by this residue.

338 The same ferroxidase assay was performed with the Enc:EncFtn complex, with wild-type and 339 EncFtn variants (Figure 6B, Figure 6-figure supplement 1). The deviations from wild-type behavior 340 were compared to those observed in the absence of the encapsulin nanocompartment (Figure 6A, 341 Figure 6-figure supplement 1). Enzymatic reaction initial rates $\left(v_{0}\right)$ were calculated for each of the 342 variants (in the first $200 \mathrm{~s}$ of the assay) and then divided by the initial rate of the corresponding 343 wild-type protein (EncFtn-WT or Enc:EncFtn-WT) (Figure 6-figure supplement 1, Tables 4, 5 and 344 6). This allowed comparison of the assay data across the two contexts for the EncFtn enzyme 
345 (encapsulated vs non-encapsulated). Our data show that the E31A and W38A variants have a

346 greater effect on activity within both systems (about 5-fold faster when compared to wild-type 347 initial rate) while the E34A variant displays a 2-fold increase in the initial velocity $v_{0}$ (Figure 6348 figure supplement 3, Table 6). The EncFtn variants and wildtype retain the same relative 349 differences in their activities whether they are associated to the encapsulin shell, or not. This 350 observation suggests that the attraction and flow restricting properties are exerted by the entry site 351 and are not changed by the sequestration of the EncFtn within the encapsulin cage.

\section{Zinc inhibition of ferroxidase activity of EncFtn}

354 In order to test the hypothesis that the entry site acts as a selectivity filter and is able to discriminate 355 between metal ions approaching the FOC, ferroxidase assays were performed with the addition of 356 zinc as a competitive inhibitor of ferroxidase activity (Le Brun et al., 1995). The activity of EncFtn 357 wild-type and variant proteins $(10 \mu \mathrm{M}$, monomer) with $50 \mu \mathrm{M} \mathrm{Fe}$ (II) was assayed in the presence of $35834 \mu \mathrm{M} \mathrm{Zn}(\mathrm{II})$ (Figure 7A). The selected zinc concentration was previously determined to be the $359 \mathrm{IC}_{50}$ for wild type EncFtn-strepII (He et al., 2019). This concentration was chosen to allow 360 identification of the impact of inhibition across the set of variant proteins. In line with our previous 361 observations, EncFtn-WT showed 54\% inhibition (He et al., 2019) (Figure 7A and B). The activity 362 of the three variant proteins (E31, E34, W38) showed a markedly increased relative inhibition when 363 compared to their activity in the absence of zinc $(88 \%, 66 \%$, and $69 \%$, respectively) (Figures 7A 364 and B). The increased inhibition seen in the variants can be explained by the changes in metal 365 coordination at the entry site. With all the variants, the abrogation of metal coordination at this site 366 permits greater access to the FOC for competing metal ions, as they are no longer effectively 367 captured in the entry site. While these data show that the entry site restricts the general accessibility 368 of the FOC to competing metal ions, they do not directly address the question of whether the site is 369 acting as a selectivity filter. 
372 To determine if zinc ions directly interact with the entry site and thus compete with iron for access

373 to the FOC, intrinsic tryptophan fluorescence was exploited to study the Trp38 microenvironment

374 in the presence and absence of zinc sulfate. Tryptophan fluorescence is the dominant source of

375 protein intrinsic fluorescence with a maximum UV absorbance at $\sim 280 \mathrm{~nm}$ and emission at $\sim 320$ -

$376350 \mathrm{~nm}$ (Teale and Weber, 1957). In addition to Trp38, EncFtn-WT possesses two more tryptophan

377 residues (W72 and W80), one phenylalanine (F89), and two tyrosine residues (Y39 and Y87).

378 Tyr39 is located in close proximity to the FOC and Glu31/Glu34, while the other aromatic residues

379 are > $10 \AA$ from both metal-coordination sites. Therefore, any observed change in the protein

380 fluorescence emission should be due to changes in the entry site, and hence to metal binding at this

381 site. This hypothesis was tested by monitoring steady state fluorescence emission of EncFtn

382 proteins over time and upon addition of increasing sub-stoichiometric concentrations of $\mathrm{Zn}$ (II). The

383 control experiment with EncFtn-W38A showed an hypsochromic shift of $8 \mathrm{~nm}$ in the emission

384 maximum $\left(\lambda_{\mathrm{EM}} \sim 322 \mathrm{~nm}\right.$ compared to $\lambda_{\mathrm{EM}} \sim 330 \mathrm{~nm}$ of EncFtn-WT) (Figure 8-figure supplement

385 1), suggesting a contribution to intrinsic fluorescence from more buried residues in the absence of

386 Trp38. Although this variant still possesses both glutamic acid residues in the entry site, no specific

387 trend was observed upon zinc addition (Figure 8, Figure 8-figure supplement 2).

389 Only wild-type EncFtn and the E31A variant showed quenching of their fluorescence emission on 390 addition of zinc, with an inflection at $\sim 1$ molar equivalent of $\mathrm{Zn}(\mathrm{II})$ per entry site (Figure 8, Figure 391 8-figure supplement 2). Variants with abrogated metal coordination (E34A and E31A/E34A) did 392 not show any specific trend, or inflection upon zinc addition (Figure 8, Figure 8-figure supplement 393 2). Moreover, tryptophan fluorescence is highly influenced by the solvent polarity of the 394 surrounding environment and fluorescence emission spectra from both E34A and E31A/E34A 395 variants exhibited a bathochromic shift of $25 \mathrm{~nm}\left(\lambda_{\mathrm{EM}} \sim 355 \mathrm{~nm}\right)$, implying an increasing polarity in 396 Trp38 surroundings (Figure 8-figure supplement 1). These data suggest that upon metal 
coordination, the Trp38 indole ring is restrained towards the gateway of the channel leading to

398 FOC.

399

400 These data suggest that metal ions can indeed interact with the entry site when it is intact (wild type), or partially present (E31A). In the absence of the entry site, $\mathrm{Zn}(\mathrm{II})$ will likely reach the FOC, an event that is not detectable with this assay, but shown by ferroxidase analysis in the presence of $\mathrm{Zn}(\mathrm{II})$ where increased inhibition of all variants was observed.

\section{Native FT-ICR mass spectrometry of ID-EncFtn}

406 Given the observation in the intrinsic tryptophan fluorescence experiments that zinc directly interacts with the entry site, we performed high-resolution native FT-ICR MS to further probe whether this site was acting as a selectivity filter to restrict the passage of competing ions to the

FOC. The high mass resolution of FT-ICR MS affords isotopic resolution of native protein

complexes and, when applied to the study of metalloproteins, allows assignment of coordinated metals with high confidence. To further aid this analysis, we also employed an isotope depletion strategy, recently developed in our laboratory (Gallagher et al., 2020). The depletion of ${ }^{13} \mathrm{C}$ and ${ }^{15} \mathrm{~N}$ stable isotopes from the EncFtn protein sample results in a dramatically reduced isotope distribution

414 in mass spectrometry analysis. This simplified signal results in increased sensitivity and, most 415 importantly for native MS analysis, reduces the occurrence of overlapping signals from proteoforms 416 of similar mass, such as complete separation of sodiated and potassiated protein ions (a common 417 observation in native protein MS). Thus, this strategy simplifies data interpretation and allows more 418 confident and precise assignment of metal bound species. Due to the quadrupole range of the FT419 ICR MS instrument used, a truncated and strep(II)-tagged version of EncFtn-WT was used as the depleted species, herein known as $I D$-EncFtn. 
422 FT-ICR analysis of apo-ID-EncFtn reveals that it exists exclusively as a monomer (Figure 9A), as

423 seen for EncFtn expressed in minimal media (He et al., 2016). Isotopic resolution confirms there is

424 no metal bound within the purified ID-EncFtn monomer; which is as predicted, due to the limited

425 bioavailability of metals in the minimal media required for the production of isotopically depleted

426 proteins (Figure 9-figure supplement 1). Titration with Fe(II) prior to MS analysis results in the

427 disappearance of the monomeric species and the appearance of a decameric charge state distribution

428 (Figure 9B, pink triangles). This result is consistent with the Fe(II)-dependent assembly of EncFtn

429 (He et al., 2016). Interestingly, titration with $\mathrm{Zn}$ (II) prior to native MS reveals a similar result with

430 decamer being formed (Figure 14C, pink triangles), supporting our previous solution-phase

431 observations that metal-mediated higher order assembly is not specific for iron (He et al., 2016).

432 Loading ID-EncFtn with Fe(II) followed by the addition of $\mathrm{Zn}$ (II) results in a decameric charge

433 distribution similar to that of the $\mathrm{Zn}$ (II)-mediated decamer (Figure 9D). Isotopic resolution cannot

434 be achieved for the decameric species due to heterogenous metal loading, but there is sufficient

435 mass resolving power to allow approximate assignment of metal-loading (Figure 9-figure

436 supplement 2). Titrations with Fe(II) reveal a decameric complex consistent with between 10 and

$43720 \mathrm{Fe}$ (II) ions bound (Figure 9-figure supplement 2A). This is more than seen previously (He et al.,

438 2016), but could be due to coordination of additional surface iron ions, or other metal adducts (such

439 as sodium or potassium, which are commonly observed in native MS). There are between 10 and 30

$440 \mathrm{Zn}(\mathrm{II})$ ions associated with the decameric species during $\mathrm{Zn}$ (II) titrations. This suggests that $\mathrm{Zn}$ (II)

441 is coordinating to $I D$-EncFtn in more of the metal binding sites than iron (Figure 9-figure

442 supplement 2B). The decameric $I D$-EncFtn species observed after the addition of both iron and zinc

443 has a higher mass than either individually (Figure 9-figure supplement 2C) - including the upper

444 range of $30 \mathrm{Zn}$ (II) ions seen in zinc titrations - suggesting both metals may be associated to the

445 complex simultaneously. No peak is observed corresponding to $10 \mathrm{Fe}$ (II) ions (iron-loaded FOC)

446 and $5 \mathrm{Zn}$ (II) ions ( $\mathrm{Zn}$ (II)-loaded entry site). 
448 We used collision-induced dissociation (CID) to gain additional understanding of metal loading in

449 ID-EncFtn. Under the correct experimental conditions, CID can lead to dissociation of a protein

450 complex whilst retaining ligand interactions and specific subcomplex assembles, and thus can

451 provide information on the topology of the original complex. Iron-loaded $I D$-EncFtn dissociates

452 predominantly into a high-charge monomer species, the so-called 'typical' dissociation product of

453 protein complexes (Hall et al., 2013). However, upon closer inspection, evidence of higher order

454 collision induced subcomplexes is present - a minor tetramer species is observed at $\mathrm{m} / \mathrm{z} 3552$

455 (charge 14+) (Figure 9-figure supplement 3A, blue circles and purple diamond respectively). This

456 species has low signal-to-noise ratio $(\mathrm{S} / \mathrm{N})$; however, its depleted isotope distribution is similar to

457 that of four ID-EncFtn monomers with two Fe(III) ions bound (Figure 9-figure supplement 3B). We

458 assign this species as of two non-FOC dimers bound together by a di-iron containing FOC, this

459 dissociation pathway is consistent with the proposed assembly of EncFtn (Ross et al., 2020) (Figure

460 9-figure supplement 3C).

461

462 In stark contrast, ID-EncFtn with coordinated $\mathrm{Zn}(\mathrm{II})$ ions dissociates into monomer and dimer

463 species (Figure 9-figure supplement 4A, blue circles and green squares respectively). Isotopic

464 resolution was achieved for the dimer species and reveals this species has a mass consistent with

465 two ID-EncFtn monomers associated two $\mathrm{Zn}$ (II) ions (Figure 9-figure supplement 4B). The

466 presence of two metal ions bound within the dimer suggests that this species is the FOC dimer with

467 the FOC occupied by two Zn(II) ions. There is no peak observed consistent with an apo-dimer, nor

468 a dimer with one, or three, $\mathrm{Zn}$ (II) ions bound. This 'atypical' dissociation pathway was previously

469 observed for EncFtn (He et al., 2016) (Figure 9-figure supplement 4C). The differing dissociation

470 pathways of zinc-coordinated $I D$-EncFtn and iron-coordinated $I D$-EncFtn suggests that zinc

471 stabilizes the FOC interface and binds with a higher affinity than iron in the FOC catalytic center;

472 this higher affinity is as predicted from the Irving-Williams series. This supports our observations

473 from the ferroxidase assay that show zinc inhibiting the FOC. Analysis of $I D$-EncFtn first loaded 
474 with iron and then subsequently challenged with zinc reveals a similar dissociation to that titrated

475 solely with zinc (Figure 9-figure supplement 5A). The dimer species observed is ID-

$476 \operatorname{EncFtn}_{2} \mathrm{Zn}(\mathrm{II})_{2}$, the same dimer species seen when titrated with zinc alone (Figure 9-figure

477 supplement 5B). This suggests that in EncFtn-WT, zinc can efficiently displace iron in the FOC,

478 that zinc inhibition acts at the catalytic ferroxidase center, and that zinc is not held within or

479 discriminated against at the entry site (Figure 9-figure supplement 5C).

480

481 In summary, we have shown that substitution of residues in the entry site triad (E31, E34, W38)

482 with non-metal binding residues results in the enhancement of enzymatic activity (Figure 6A). Our

483 crystal structures support the conclusion that this is a consequence of the creation of a wider and

484 more loosely coordinating entry site, which allows the faster passage of metal ions to the FOC due

485 to a reduced energy barrier at this site (Figure 4). Furthermore, when these key residues are

486 removed, the protein is more susceptible to inhibition by $\mathrm{Zn}(\mathrm{II})$. 


\section{Discussion}

488 Our work presents a comprehensive structure/function study investigating the role of the entry site 489 proximal to the ferroxidase center (FOC) in encapsulated ferritin-like proteins. To investigate the 490 role of this site we produced variant proteins with amino-acid substitutions in residues in this site to 491 replace metal coordinating residues in the R. rubrum EncFtn protein with alanine (E31A, E34A) 492 and to remove the large tryptophan side chain proximal to this site (W38A/G).

494 Solution and gas-phase analyses of variant proteins showed that, in contrast to the FOC, removal of 495 the metal coordinating ligands (E31A/E34A) did not have a significant effect on protein 496 oligomerization; however, removal of the Trp38 side chain had a significant destabilizing effect on 497 the quaternary structure of the protein. X-ray crystal structures of the E31A and E34A variants 498 highlighted changes in metal coordination at the entry site. The effect of these changes on the 499 activity of the protein was tested using ferroxidase assays and zinc inhibition experiments. Removal 500 of the Glu31 and Trp38 side chains significantly enhanced the activity of the enzyme; while 501 removal of metal coordinating residues increased the susceptibility of the protein to inhibition by 502 zinc. Investigation of the EncFtn intrinsic fluorescence emission properties upon zinc binding 503 revealed coordination in the entry site when this is intact or partially formed (WT and E31A, respectively), confirming that this site acts as an additional metal binding site prior to the FOC.

506 High resolution MS analysis of $I D$-EncFtn metal binding reveals that $I D$-EncFtn decamer assembly 507 can be induced by iron and zinc ions. Furthermore, zinc appears to bind within the FOC more 508 tightly than iron and stabilizes the FOC dimer. When $I D$-EncFtn is titrated with iron and 509 subsequently zinc, only zinc is observed bound in $I D$-EncFtn subcomplexes, indicating that zinc 510 displaces iron from the FOC. 
512 Taken together, these results imply that the entry site has a lower affinity for metal ions than the

513 ferroxidase center and that in accord with the Irving-Williams series the FOC forms more stable

514 complexes with zinc than iron. However, bacterial cells buffer metal concentrations via a

515 polydisperse buffer in the order of the Irving-William series (Foster et al., 2014; Frausto da Silva

516 and Williams, 1991; Reyes-Caballero et al., 2011; Tottey et al., 2008), resulting in highly

517 competitive $\mathrm{Zn}$ (II) ions being buffered to lower available levels than $\mathrm{Fe}(\mathrm{II})$, thus presumably

518 preventing the mis-metalation of ferritin sites in vivo.

520 These observations support the hypothesis that the entry site has a dual function, in attracting metal

521 ions to the catalytic site, and as a flow restrictor to limit the movement of metal ions to the FOC and

522 thus slow the rate of iron oxidation (Figure $2 \mathrm{E} / \mathrm{G}$ ). Our results confirm that the ferroxidase center is

523 indeed the active site of this enzyme, as the loss of the entry site enhances enzyme activity rather

524 than abrogates it. Why the EncFtn protein has evolved a mechanism to effectively slow its activity

525 is still an open question. There may be a trade-off between substrate turnover and the availability of

526 a sink for the electrons liberated from the iron in the ferroxidase center. The catalytic mechanism

527 and electron sink for ferritins is still a subject of vigorous debate. The EncFtn family presents a

528 unique structural arrangement of the active site, which will no doubt present a distinct mechanism

529 to other members of the ferritin family when probed further (W. R. Hagen et al., 2017). The entry

530 site may well provide a brake to ensure productive coupling of iron oxidation and mineralization.

532 Encapsulation of the EncFtn protein within the encapsulin nanocage enhances the activity of all of

533 the EncFtn variants (Figure 6), but does not change the way in which modifications to the entry site

534 affect the catalytic activity, indicating that the function of the entry site is not changed through

535 association with the encapsulin shell. These results suggest that the encapsulin shell acts to guide

536 productive iron ion interactions with the EncFtn protein; indeed, our previous work showed that the

537 encapsulin shell interacts with a significant amount of iron in the absence of the EncFtn protein. 
538 This warrants future investigation into the ability of the encapsulin shell to conduct metal ions to

539 the EncFtn active site and the role of the encapsulin shell pores in the access of substrates to the 540 encapsulated enzyme. 


\section{$541 \quad$ Materials and Methods}

\begin{tabular}{|c|c|c|c|c|}
\hline \multicolumn{5}{|c|}{ Key Resources Table } \\
\hline $\begin{array}{l}\text { Reagent type } \\
\text { (species) or } \\
\text { resource }\end{array}$ & Designation & $\begin{array}{l}\text { Source or } \\
\text { reference }\end{array}$ & Identifiers & $\begin{array}{l}\text { Additional } \\
\text { information }\end{array}$ \\
\hline $\begin{array}{l}\text { strain, strain } \\
\text { background } \\
\text { (Escherichia } \\
\text { coli) }\end{array}$ & BL21(DE3) & $\begin{array}{l}\text { Cambridge } \\
\text { Biosciences }\end{array}$ & 60401 & $\begin{array}{l}\text { chemically } \\
\text { competent }\end{array}$ \\
\hline $\begin{array}{l}\text { recombinant } \\
\text { DNA reagent }\end{array}$ & pACYCDuet-1 & Novagen & 71147 & $\begin{array}{l}\text { vector for protein } \\
\text { expression in } E \text {. } \\
\text { coli }\end{array}$ \\
\hline $\begin{array}{l}\text { sequence- } \\
\text { based reagent }\end{array}$ & Primers used in this study & IDT & & See Table 8 \\
\hline $\begin{array}{l}\text { commercial } \\
\text { assay or kit }\end{array}$ & Pierce $^{\mathrm{TM}}$ BCA Assay kit & $\begin{array}{l}\text { Thermo Fisher } \\
\text { Scientific }\end{array}$ & 23225 & \\
\hline $\begin{array}{l}\text { commercial } \\
\text { assay or kit }\end{array}$ & Stratagene QuikChange kit & Agilent & 200523 & \\
\hline $\begin{array}{l}\text { chemical } \\
\text { compound, drug }\end{array}$ & Lysozyme & Sigma-Aldrich & L6876 & \\
\hline $\begin{array}{l}\text { chemical } \\
\text { compound, drug }\end{array}$ & Benzonase & Sigma-Aldrich & E1014 & \\
\hline $\begin{array}{l}\text { chemical } \\
\text { compound, drug }\end{array}$ & PEG 3350 & Sigma-Aldrich & 1546547 & \\
\hline $\begin{array}{l}\text { chemical } \\
\text { compound, drug }\end{array}$ & Calcium acetate & Sigma-Aldrich & 21056 & \\
\hline
\end{tabular}




\begin{tabular}{|c|c|c|c|c|}
\hline $\begin{array}{l}\text { chemical } \\
\text { compound, drug }\end{array}$ & Iron sulfate & Sigma-Aldrich & 1270355 & \\
\hline $\begin{array}{l}\text { chemical } \\
\text { compound, drug }\end{array}$ & PEG 200 & Sigma-Aldrich & 807483 & Cryoprotectant \\
\hline $\begin{array}{l}\text { chemical } \\
\text { compound, drug }\end{array}$ & 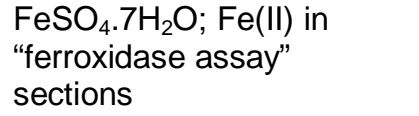 & Sigma-Aldrich & 1270355 & \\
\hline $\begin{array}{l}\text { chemical } \\
\text { compound, drug }\end{array}$ & $\begin{array}{l}\mathrm{ZnSO}_{4 .} 7 \mathrm{H}_{2} \mathrm{O} ; \mathrm{Zn}(\mathrm{II}) \text { in "zinc } \\
\text { inhibition of ferroxidase } \\
\text { assays" and "steady state } \\
\text { fluorescence" sections }\end{array}$ & Sigma-Aldrich & 204986 & \\
\hline $\begin{array}{l}\text { chemical } \\
\text { compound, drug }\end{array}$ & $\begin{array}{l}{ }^{14} \mathrm{~N}(99.99 \%) \text {-ammonium } \\
\text { sulfate }\end{array}$ & ISOTEC & 485411 & \\
\hline $\begin{array}{l}\text { chemical } \\
\text { compound, drug }\end{array}$ & ${ }^{12} \mathrm{C}(99.9 \%)$-glucose & $\begin{array}{l}\text { Cambridge } \\
\text { Isotope } \\
\text { Laboratories }\end{array}$ & $\begin{array}{l}\text { CLM- } \\
4819-1\end{array}$ & \\
\hline $\begin{array}{l}\text { chemical } \\
\text { compound, drug }\end{array}$ & $\begin{array}{l}\text { Iron(II) chloride } \\
\text { tetrahydrate; Fe(II) in the } \\
\text { "Native FT-ICR mass } \\
\text { spectrometry" section }\end{array}$ & Sigma-Aldrich & F2130 & \\
\hline $\begin{array}{l}\text { chemical } \\
\text { compound, drug }\end{array}$ & $\begin{array}{l}\text { Zinc acetate; } \mathrm{Zn}(\mathrm{II}) \text { in the } \\
\text { "Native FT-ICR mass } \\
\text { spectrometry" section }\end{array}$ & Sigma-Aldrich & 383317 & \\
\hline $\begin{array}{l}\text { software, } \\
\text { algorithm }\end{array}$ & MassLynx & $\begin{array}{l}\text { Waters } \\
\text { Corporation }\end{array}$ & & \\
\hline $\begin{array}{l}\text { software, } \\
\text { algorithm }\end{array}$ & DriftScope & $\begin{array}{l}\text { Waters } \\
\text { Corporation }\end{array}$ & & \\
\hline $\begin{array}{l}\text { software, } \\
\text { algorithm }\end{array}$ & Spyder CIUsuite & $\begin{array}{l}\text { Dixit et al., } \\
2018\end{array}$ & & \\
\hline $\begin{array}{l}\text { software, } \\
\text { algorithm }\end{array}$ & IMPACT & $\begin{array}{l}\text { Marklund et al., } \\
2015\end{array}$ & & \\
\hline
\end{tabular}




\begin{tabular}{|c|c|c|c|c|}
\hline $\begin{array}{l}\text { software, } \\
\text { algorithm }\end{array}$ & Data Analysis & $\begin{array}{l}\text { Bruker } \\
\text { Daltonics }\end{array}$ & & \\
\hline $\begin{array}{l}\text { software, } \\
\text { algorithm }\end{array}$ & Isotope Pattern & $\begin{array}{l}\text { Bruker } \\
\text { Daltonics }\end{array}$ & & \\
\hline $\begin{array}{l}\text { software, } \\
\text { algorithm }\end{array}$ & Prism 8 & GraphPad & & \\
\hline $\begin{array}{l}\text { software, } \\
\text { algorithm }\end{array}$ & Origin 2016 & OriginLab & & \\
\hline $\begin{array}{l}\text { software, } \\
\text { algorithm }\end{array}$ & Open Source PyMOL & $\begin{array}{l}\text { Schroedinger } \\
\text { LLC }\end{array}$ & & \\
\hline $\begin{array}{l}\text { software, } \\
\text { algorithm }\end{array}$ & Phaser & $\begin{array}{l}\text { McCoy et al., } \\
2007\end{array}$ & & \\
\hline $\begin{array}{l}\text { software, } \\
\text { algorithm }\end{array}$ & Phenix.autobuild & $\begin{array}{l}\text { Adams et al., } \\
2010\end{array}$ & & \\
\hline $\begin{array}{l}\text { software, } \\
\text { algorithm }\end{array}$ & Phenix.refine & $\begin{array}{l}\text { Afonine et al., } \\
2012\end{array}$ & & \\
\hline $\begin{array}{l}\text { software, } \\
\text { algorithm }\end{array}$ & Coot & $\begin{array}{l}\text { Emsley et al., } \\
2010\end{array}$ & & \\
\hline $\begin{array}{l}\text { software, } \\
\text { algorithm }\end{array}$ & MolProbity & $\begin{array}{l}\text { Chen et al., } \\
2010\end{array}$ & & \\
\hline other & $\begin{array}{l}\text { HiPrep Q HP; anion } \\
\text { exchange column }\end{array}$ & GE Healthcare & $\begin{array}{l}\text { GE29- } \\
0181-82\end{array}$ & \\
\hline other & $\begin{array}{l}\text { HiLoad } 16 / 60 \text { Superdex } \\
200 ; \text { size exclusion column; } \\
\text { S200 }\end{array}$ & GE Healthcare & $\begin{array}{l}\text { GE28- } \\
9893-35\end{array}$ & \\
\hline other & HisTrap column & GE Healthcare & $\begin{array}{l}\text { GE17- } \\
5255-01\end{array}$ & $5 \mathrm{~mL}$ column \\
\hline other & Strep-Trap HP column & GE Healthcare & $\begin{array}{l}\text { GE28- } \\
9075-48\end{array}$ & $5 \mathrm{~mL}$ column \\
\hline
\end{tabular}




\section{Cloning}

543 Expression constructs for the R. rubrum EncFtn protein (pACYCDuet-1-Rru_EncFtn) and

544 Enc:EncFtn protein complex (pACYCDuet-1-Enc:EncFtn) were produced in the previous work (He

545 et al., 2016) Site-directed mutagenesis was performed using Stratagene QuikChange kit following

546 manufacturer instructions. Protein nomenclature used throughout the text is shown in Table 7.

547 Primers used in this work for this purpose are listed in Table 8

\section{Protein production and purification}

550 Expression plasmids for the R. rubrum EncFtn protein and Enc:EncFtn complex were transformed 551 into competent Escherichia coli BL21(DE3) cells and grown in LB medium supplemented with 552 appropriate antibiotics, and expressed as described previously (He et al., 2019, 2016). Protein 553 sequences are listed in Table 9.

EncFtn and its variants, were purified as described in (He et al., 2019). Briefly, the proteins were 556 purified by combining anion exchange chromatography (AXC) and size exclusion chromatography 557 (SEC). Purity of protein samples was analyzed by $15 \%$ SDS-PAGE.

Enc:EncFtn wild-type and variant complex cell pellets were resuspended in 10-times (v/w) of Lysis Buffer (20 mM HEPES pH 8.0, $2 \mathrm{mM} \mathrm{MgCl} 2,1 \mathrm{mg} / \mathrm{ml}$ lysozyme, 20 units/ml benzonase). Cells

561 were sonicated on ice (5 minutes at 30 seconds on/off cycles, $35 \%$ amplitude), followed by 562 incubation for 30 minutes at $37{ }^{\circ} \mathrm{C}$ in a water bath. Cell lysate was clarified by centrifugation $563\left(35,000 \times \mathrm{g}, 30\right.$ minutes, $\left.4{ }^{\circ} \mathrm{C}\right)$ and the supernatant was collected and incubated for 10 minutes at 80 $564{ }^{\circ} \mathrm{C}$ in a water bath. After cooling the sample was centrifuged again (30 minutes, 35,000 x g, $4{ }^{\circ} \mathrm{C}$ ), 565 and the supernatant was collected and filtered using a $0.22 \mu \mathrm{m}$ syringe filter (Millipore, UK). 566 Enc:EncFtn protein complex sample was loaded onto a $20 \mathrm{ml}$ anion exchange column (Hi-Prep Q 567 HP, GE Healthcare) pre-equilibrated with Buffer QA (50 mM Tris, pH 8.0). Un-bound protein was 
washed with Buffer QA. A step gradient elution of 20 column volumes was performed by mixing

Buffers QA and QB (50 mM Tris, pH 8.0, $1 \mathrm{M} \mathrm{NaCl)}$ to $100 \%$ QB. Since Enc:EncFtn does not

570 bind the anion exchange column, proteins of interest were found in flow-through sample, as

571 confirmed by $15 \%$ SDS-PAGE. Protein was concentrated using a Vivaspin centrifugal concentrator

572 (MWCO $10 \mathrm{kDa}$, Sartorius) following the manufacturer's instructions. Concentrated protein was

573 then applied to a size exclusion column (HiLoad 16/60 Superdex 200, GE Healthcare) pre-

574 equilibrated with Buffer GF (50 mM Tris, $\mathrm{pH} 8.0,150 \mathrm{mM} \mathrm{NaCl})$. Fractions of interest were run on

575 a $15 \%$ SDS-PAGE to assess protein purity and oligomeric state, and further concentrated using a

576 Vivaspin centrifugal concentrator as before. After concentration, protein samples were analyzed by

577 10\% Tricine-SDS-PAGE (Schägger, 2006) in order to resolve bands around $30 \mathrm{kDa}$. Elution

578 volumes of EncFtn and Enc:EncFtn complexes from the size exclusion column are listed in Table 2.

579

580 His-tagged protein production and purification

581 Hexahistidine tagged EncFtn-E31A and -E34A variants (EncFtn-sH) were produced in E. coli 582 BL21(DE3) as described above and purified following the same protocols as previously described 583 (He et al., 2016). Briefly, a $5 \mathrm{ml}$ HisTrap column (GE Healthcare, UK) was used for immobilized 584 metal affinity chromatography (IMAC), followed by size exclusion chromatography (HiLoad 16/60 585 Superdex 200, GE Healthcare) using the protocol described above.

\section{Isotopically depleted strepII-tagged protein production and purification}

588 To produce isotopically depleted EncFtn proteins, competent E. coli BL21 (DE3) cells were 589 transformed with the required expression plasmid. A single colony was used to inoculate $10 \mathrm{ml}$ of 590 LB media supplemented with the appropriate antibiotic, before overnight incubation at $37{ }^{\circ} \mathrm{C}$. This 591 was then used to inoculate $500 \mathrm{ml}$ of $2 \mathrm{x}$ YT media, incubated at $37^{\circ} \mathrm{C}$ until an $\mathrm{OD}_{600} 0.6-0.8$ was 592 obtained, at which point the cell culture was centrifuged at $5000 \mathrm{x} \mathrm{g}$ at $4{ }^{\circ} \mathrm{C}$ for 20 minutes $(200 \mathrm{ml}$ 593 per expression culture required). The pellet was washed with $\mathrm{M} 9$ salts solution $\left(33.9 \mathrm{~g} / \mathrm{L} \mathrm{Na}_{2} \mathrm{HPO}_{4}\right.$, 
$\left.59415 \mathrm{~g} / \mathrm{L} \mathrm{KH}_{2} \mathrm{PO}_{4}, 2.5 \mathrm{~g} / \mathrm{L} \mathrm{NaCl}\right)$ and suspended in $100 \mathrm{ml} \mathrm{M} 9$ minimal media. Isotopically depleted 595 M9 minimal media was supplemented with ${ }^{12} \mathrm{C}$ (99.9\%)-glucose (Cambridge Isotope Laboratories) 596 and ${ }^{14} \mathrm{~N}(99.99 \%)$-ammonium sulfate. The M9 minimal media cultures were further incubated at 37

$597{ }^{\circ} \mathrm{C}$ for 1 hour, before protein expression was induced and stored as previously described (Gallagher 598 et al., 2020).

599

600 Isotopically depleted strepII-tagged EncFtn (ID-EncFtn) was purified as reported in (He et al. 601 2019). Cells were suspended in 10x (v/w) Buffer W (100 mM Tris pH 8.0, $150 \mathrm{mM} \mathrm{NaCl}$ ), 602 sonicated and clarified by centrifugation. Cell lysate was loaded onto a Strep-Trap HP column (5 $603 \mathrm{~mL}$, GE Healthcare), equilibrated according to manufacturer's instructions, and unbound protein 604 was washed out with Buffer W (5 column volumes). ID-EncFtn was eluted by Buffer E (100 mM 605 Tris $\mathrm{pH} 8.0,150 \mathrm{mM} \mathrm{NaCl}, 2.5 \mathrm{mM}$ desthiobiotin).

606

\section{Protein quantification}

608 Both untagged and His-tagged EncFtn proteins were quantified using the Pierce BCA Assay kit 609 (Thermo Fisher Scientific) following the manufacturer's instructions for the Test-tube procedure. 610 Concentration of Enc:EncFtn proteins was determined using the Beer-Lambert equation, measuring 611 absorbance at $280 \mathrm{~nm}$ with a Nanodrop Spectrophotometer (Thermo Scientific) and using an 612 extinction coefficient calculated by ProtParam tool on the Expasy platform entering a sequence 613 composed of $3 \times$ Enc and $2 \times$ Enc-Ftn sequences. This ratio was determined by examination of 614 SDS-PAGE gels of Enc:EncFtn proteins and densitometry of bands.

615

\section{Transmission electron microscopy}

617 TEM imaging was performed as previously described (He et al., 2016) on purified Enc:EncFtn 618 proteins. Proteins were diluted in Buffer GF to a final concentration of $0.1 \mathrm{mg} / \mathrm{ml}$ before being 619 spotted on glow-discharged 300 mesh carbon-coated copper grids. Excess liquid was removed by 
620 blotting with filter paper (Whatman, UK) before the sample was washed three times with distilled 621 water prior to being stained with $0.2 \%$ uranyl acetate, blotted again, and air-dried. Grids were 622 imaged using a Hitachi HT7800 transmission electron microscope and images were collected with 623 an EMSIS Xarosa camera.

624

\section{Protein crystallization and X-ray data collection}

626 EncFtn-sH variants (E31A or E34A) were concentrated to $10 \mathrm{mg} / \mathrm{ml}$ (based on extinction 627 coefficient calculation) and subjected to crystallization under similar conditions to the wild-type 628 protein (WT) (Table 10). Crystallization drops were set up in 24-well Linbro plates using the hanging drop vapor diffusion method at $292 \mathrm{~K}$. Glass coverslips were set up with 1-2 $\mu$ protein

630 mixed with $1 \mu \mathrm{l}$ well solution and sealed over $1 \mathrm{ml}$ of well solution. Crystals appeared after one 631 week to two months and were mounted using a LithoLoop (Molecular Dimensions Limited, UK), 632 transferred briefly to a cryoprotection solution containing well solution supplemented with $1 \mathrm{mM}$ $633 \mathrm{FeSO}_{4}$ (in $0.1 \%(\mathrm{v} / \mathrm{v}) \mathrm{HCl}$ ) and $20 \%$ (v/v) PEG 200, and were subsequently flash cooled in liquid 634 nitrogen.

635

636 All crystallographic datasets were collected at 10-100 eV above the experimentally determined Fe$637 K \alpha$ edge on the macromolecular crystallography beamlines at Diamond Light Source (Didcot, UK) 638 at $100 \mathrm{~K}$ using Pilatus 6M detectors. Diffraction data were integrated and scaled using XDS 639 (Kabsch, 2010) and symmetry related reflections were merged with Aimless (Evans, 2011). Data 640 collection statistics are shown in Table 11. The resolution cut-off used for structure determination 641 and refinement was determined based on the $\mathrm{CC}_{1 / 2}$ criterion proposed by (Karplus and Diederichs, 642 2012).

643 The structures of the EncFtn-sH variants were determined by molecular replacement using 644 decameric wild-type protein (PDB ID: 5DA5) as the search model (He et al., 2016). A single 
645 solution comprising three decamers in the asymmetric unit was found by molecular replacement

646 using Phaser (McCoy et al., 2007). The initial model was rebuilt using Phenix.autobuild (Adams et

647 al., 2010) followed by cycles of refinement with Phenix.refine (Afonine et al., 2012), with manual

648 rebuilding and model inspection in Coot (Emsley et al., 2010). The final model was refined with

649 isotropic B-factors, torsional NCS restraints, and with anomalous group refinement to correctly

650 model the iron ions in the ferroxidase center. The model was validated using MolProbity (Chen et

651 al., 2010). Structural superimpositions were calculated using Coot (Emsley et al., 2010).

652 Crystallographic figures were generated with PyMOL. Model refinement statistics are shown in

653 Table 11. The final models and experimental data are deposited in the PDB.

654

\section{Mass spectrometry analysis}

656 Sample preparation, instrumentation, native MS conditions, ion mobility-MS conditions and the 657 method of collision cross section (CCS) determination have all been reported in previous works by 658 our group (He et al., 2016; Ross et al., 2020). For collision induced unfolding (CIU) experiments, 659 protein samples were prepared and the Synapt G2 was set up as for IM-MS. Samples were analyzed 660 with incremental increasing trap voltages between $10 \mathrm{~V}$ to $60 \mathrm{~V}$, using $2 \mathrm{~V}$ increments. Data was 661 processed using Spyder CIUSuite (Dixit et al., 2018) .

662

663 Ferroxidase assay of EncFtn proteins

664 Enzymatic activity of EncFtn proteins was tested by ferroxidase assay, as previously described (He 665 et al., 2019). $\mathrm{Fe}(\mathrm{II})$ aliquots were prepared under anaerobic conditions by dissolving $\mathrm{FeSO}_{4} \cdot 7 \mathrm{H}_{2} \mathrm{O}$ in $6660.1 \%(\mathrm{v} / \mathrm{v}) \mathrm{HCl}$. Purified protein was diluted anaerobically in Buffer H (10 mM HEPES, pH 8.0, $667150 \mathrm{mM} \mathrm{NaCl}$ ), previously purged with gaseous nitrogen, to a final concentration of $10 \mu \mathrm{M}$ 668 (EncFtn). 
669 Protein and ferrous iron samples were added to a quartz cuvette (Hellma) under aerobic conditions

670 at a final concentration of $10 \mu \mathrm{M}$ and $50 \mu \mathrm{M}$, respectively, corresponding to a FOC:Fe(II) ratio of

$671 \quad 1: 10$

672

673 Absorbance at $315 \mathrm{~nm}$ was recorded every second for $1500 \mathrm{~s}$ by a UV-visible spectrophotometer

674 (PerkinElmer Lambda 35), using the TimeDrive software. The same experiment was performed in

675 the absence of the enzyme to determine the oxidation of ferrous salts by atmospheric oxygen.

676 The same setup was adopted for recording the activity of EncFtn-E34A and EncFtn-E31A/E34A in

677 a separate assay at higher concentration $(20 \mu \mathrm{M}$ EncFtn and $100 \mu \mathrm{M} \mathrm{Fe}(\mathrm{II}))$ for comparison

678 purposes. Data presented here are the mean of three technical replicates of time zero-subtracted

679 progress curves with standard deviations calculated from the mean.

680

681 Calculation of the EncFtn enzymatic reaction initial rate $\left(v_{0}\right)$ was made by applying the Linear 682 Regression tool in GraphPad (Prism8) on the absorbance at $315 \mathrm{~nm}$ measured for the first $200 \mathrm{~s}$, 683 when curves are still linear and following an order zero kinetics (Figure 6-supplement 2, Table 4).

684 Slopes obtained from these curves correspond to initial reaction rate. $v_{0}{ }^{\text {variant }} / v_{0}{ }^{\text {wild-type }}$ factors were 685 calculated by dividing the initial rates of the variant enzymes by the initial rate of the wild-type 686 protein (Table 6).

687

\section{Ferroxidase assay of Enc:EncFtn protein complexes}

689 Ferroxidase assay of Enc:EncFtn protein complexes was performed in the same conditions as those 690 used for EncFtn, but with different protein and iron salt concentration. Enc:EncFtn was diluted to a 691 final concentration of $25 \mu \mathrm{M}$ which corresponds to $10 \mu \mathrm{M}$ EncFtn based on a 3:2 Enc:EncFtn ratio, 692 as previously observed by SDS-PAGE by our group (Figure 1A in (He et al., 2016). Fe(II) sample 693 was diluted to $50 \mu \mathrm{M}$ in the reaction system to maintain a final ratio of 1:10 FOC:Fe(II). 
694 Calculation of the Enc-EncFtn enzymatic reaction initial rate $\left(v_{0}\right)$ and $v_{0}$ variant $/ v_{0}$ wild-type factors was

695 carried out as described in the above section (Figure 6-supplement 2, Tables 5 and 6).

696

697

\section{Zinc inhibition of ferroxidase activity of EncFtn proteins}

698 Ferroxidase assay was performed as above with EncFtn $(10 \mu \mathrm{M})$ and Fe(II) samples $(50 \mu \mathrm{M})$ in the 699 presence of $34 \mu \mathrm{M} \mathrm{ZnSO} \cdot 7 \mathrm{H}_{2} \mathrm{O}$. The chosen concentration corresponds to the $\mathrm{IC}_{50}$ value 700 previously determined for EncFtn-StrepII, under the same experimental conditions by our group 701 (He et al., 2019). Oxygen-free metal samples were added to the quartz cuvette under aerobic 702 conditions, followed by the protein sample. Data were replicated three times and means and 703 standard deviation of time zero-subtracted progress curves were calculated. A negative control was 704 performed by monitoring $\mathrm{A}_{315}$ of $\mathrm{Zn}(\mathrm{II})$ and $\mathrm{Fe}(\mathrm{II})$ salts mixed in the absence of enzyme.

\section{Monitoring quenching of protein intrinsic fluorescence upon metal-binding}

707 Experiments were carried out aerobically in a quartz cuvette (Hellma), using a Cary Eclipse 708 Fluorescence spectrophotometer. Protein was diluted in Buffer GF to a final concentration of 20 $\mu \mathrm{M}$, corresponding to $10 \mu \mathrm{M}$ for the entry site. $\mathrm{ZnSO}_{4} \cdot 7 \mathrm{H}_{2} \mathrm{O}$ stock was prepared in deionized water. The instrument excitation wavelength was set to $280 \mathrm{~nm}$, corresponding to maximum 711 absorption for tryptophan residues.

713 Two distinct modes of detection were used; Kinetic option on the Analysis software package was 714 chosen to record protein fluorescence emission signal at specific wavelengths over time. Pre-scans 715 were carried out to find the optimal emission wavelength (ranging from $322 \mathrm{~nm}$ to $355 \mathrm{~nm}$ ) for each protein variant. Metal aliquots ( 0.15 or 0.3 molar equivalents) were added to the cuvette while

717 pausing the data collection for fewer than five seconds. The final data represent average of 10 data 718 points at equilibrium upon each metal addition. 
719 The Scan option of the Analysis software package was chosen to record emission in the 290-400

$720 \mathrm{~nm}$ range, allowing detection of possible shifts in emission peak maximum upon metal addition.

721 Spectra were recorded in triplicate at equilibrium.

722

723 Native FT-ICR mass spectrometry

724 High resolution native mass spectrometry was performed on a 12T SolariX 2XR FT-ICR MS

725 (Bruker Daltonics) equipped with a nanoelectrospray source. Protein samples were buffer 726 exchanged into ammonium acetate (100 mM; pH 8.0) prior to direct infusion. Source conditions 727 and ion optics were optimized to transmit native proteins ions and when required, Continual 728 Accumulation of Selected Ions (CASI) was employed to isolate charge states of interest. Typically, 7292 Megaword data was collected in QPD $(2 \omega)$ mode to produce a 6 second FID, which resulted in a 730 typical mass resolving power of ca. 300,000. The resulting data was processed using Data Analysis 731 (Bruker Daltonics) and theoretical isotope patterns were calculated using IsotopePattern (Bruker

732 Daltonics). For metal titrations, fresh iron(II) chloride tetrahydrate or zinc acetate in $0.1 \%$ (v/v) $\mathrm{HCl}$ 733 was added to $I D$-EncFtn (1:1 metal:protein concentration) prior to buffer exchange into ammonium 734 acetate (100 mM; pH 8.0).

735

736 Accession codes and datasets

737 Data sets supporting this paper have been deposited in appropriate public data repositories. Please 738 see figure legends and tables for links to these. 


\section{References}

Adams PD, Afonine P V., Bunkóczi G, Chen VB, Davis IW, Echols N, Headd JJ, Hung L-W, Kapral GJ, Grosse-Kunstleve RW, McCoy AJ, Moriarty NW, Oeffner R, Read RJ, Richardson DC, Richardson JS, Terwilliger TC, Zwart PH. 2010. PHENIX $\square$ : a comprehensive Pythonbased system for macromolecular structure solution. Acta Crystallogr Sect D Biol Crystallogr 66:213-221. doi:10.1107/S0907444909052925

Afonine P V., Grosse-Kunstleve RW, Echols N, Headd JJ, Moriarty NW, Mustyakimov M, Terwilliger TC, Urzhumtsev A, Zwart PH, Adams PD. 2012. Towards automated crystallographic structure refinement with phenix.refine. Acta Crystallogr Sect D Biol Crystallogr 68:352-367. doi:10.1107/S0907444912001308

Almiron M, Link AJ, Furlong D, Kolter R. 1992. A novel DNA-binding protein with regulatory and protective roles in starved Escherichia coli. Genes Dev 6:2646-2654. doi:10.1101/gad.6.12b.2646

Andrews S. 1998. Iron storage in bacteria. Adv Microb Physiol 40:281-351.

Andrews SC. 2010. The Ferritin-like superfamily: Evolution of the biological iron storeman from a rubrerythrin-like ancestor. Biochim Biophys Acta - Gen Subj 1800:691-705. doi:10.1016/j.bbagen.2010.05.010

Baaghil S, Lewin A, Moore GR, Le Brun NE. 2003. Core Formation in Escherichia coli Bacterioferritin Requires a Functional Ferroxidase Center $\dagger$. Biochemistry 42:14047-14056. doi:10.1021/bi035253u

Behera RK, Torres R, Tosha T, Bradley JM, Goulding CW, Theil EC. 2015. Fe2+ substrate transport through ferritin protein cage ion channels influences enzyme activity and biomineralization. JBIC J Biol Inorg Chem 20:957-969. doi:10.1007/s00775-015-1279-x

Bellapadrona G, Stefanini S, Zamparelli C, Theil EC, Chiancone E. 2009. Iron Translocation into and out of Listeria innocua Dps and Size Distribution of the Protein-enclosed Nanomineral Are Modulated by the Electrostatic Gradient at the 3-fold "Ferritin-like" Pores. J Biol Chem 284:19101-19109. doi:10.1074/jbc.M109.014670

Cardenas JP, Quatrini R, Holmes DS. 2016. Aerobic Lineage of the Oxidative Stress Response Protein Rubrerythrin Emerged in an Ancient Microaerobic, (Hyper)Thermophilic Environment. Front Microbiol 7. doi:10.3389/fmicb.2016.01822

Chasteen ND, Harrison PM. 1999. Mineralization in Ferritin: An Efficient Means of Iron Storage. $J$ Struct Biol 126:182-194. doi:10.1006/jsbi.1999.4118

Chen V, Arendall W, Headd J, Keedy D, Immormino R, Kapral G, Murray L, Richardson J, Richardson D. 2010. MolProbity: all-atom structure validation for macromolecular crystallography. Acta Crystallogr Sect D Biol Crystallogr 66:12-21. doi:10.1107/S0907444909042073

Chiancone E, Ceci P. 2010. The multifaceted capacity of Dps proteins to combat bacterial stress conditions: Detoxification of iron and hydrogen peroxide and DNA binding. Biochim Biophys Acta - Gen Subj 1800:798-805. doi:10.1016/j.bbagen.2010.01.013

Choi SH, Baumler DJ, Kaspar CW. 2000. Contribution of dps to Acid Stress Tolerance and Oxidative Stress Tolerance in Escherichia coli O157:H7. Appl Environ Microbiol 66:39113916. doi:10.1128/AEM.66.9.3911-3916.2000

De Martino M, Ershov D, van den Berg PJ, Tans SJ, Meyer AS. 2016. Single-Cell Analysis of the Dps Response to Oxidative Stress. J Bacteriol 198:1662-1674. doi:10.1128/JB.00239-16

Dillard BD, Demick JM, Adams MWW, Lanzilotta WN. 2011. A cryo-crystallographic time course for peroxide reduction by rubrerythrin from Pyrococcus furiosus. JBIC J Biol Inorg Chem 16:949-959. doi:10.1007/s00775-011-0795-6

Dixit SM, Polasky DA, Ruotolo BT. 2018. Collision induced unfolding of isolated proteins in the gas phase: past, present, and future. Curr Opin Chem Biol 42:93-100. doi:10.1016/j.cbpa.2017.11.010

Ebrahimi KH, Bill E, Hagedoorn P-L, Hagen WR. 2016. Spectroscopic evidence for the role of a 
801

802

803

804

805

806

807

808

809

810

811

812

813

814

815

816

817

818

819

820

821

822

823

824

825

826

827

828

829

830

831

832

833

834

835

836

837

838

839

840

841

site of the di-iron catalytic center of ferritins in tuning the kinetics of $\mathrm{Fe}(<\mathrm{scp}>\mathrm{ii}</ \mathrm{scp}>$ ) oxidation. Mol Biosyst 12:3576-3588. doi:10.1039/C6MB00235H

Ebrahimi KH, Hagedoorn P-L, Jongejan J a, Hagen WR. 2009. Catalysis of iron core formation in Pyrococcus furiosus ferritin. J Biol Inorg Chem 14:1265-74. doi:10.1007/s00775-009-0571-z

Emsley P, Lohkamp B, Scott WG, Cowtan K. 2010. Features and development of Coot. Acta Crystallogr Sect D Biol Crystallogr 66:486-501. doi:10.1107/S0907444910007493

Eschweiler JD, Rabuck-Gibbons JN, Tian Y, Ruotolo BT. 2015. CIUSuite: A Quantitative Analysis Package for Collision Induced Unfolding Measurements of Gas-Phase Protein Ions. Anal Chem 87:11516-11522. doi:10.1021/acs.analchem.5b03292

Evans PR. 2011. An introduction to data reduction: space-group determination, scaling and intensity statistics. Acta Crystallogr Sect D Biol Crystallogr 67:282-292. doi:10.1107/S090744491003982X

Foster AW, Osman D, Robinson NJ. 2014. Metal Preferences and Metallation. J Biol Chem 289:28095-28103. doi:10.1074/jbc.R114.588145

Frausto da Silva J, Williams R. 1991. The biological chemistry of the elements: the inorganic chemistry of life. Oxford Univ Press 20:62-63. doi:10.1016/0307-4412(92)90039-O

Frolow F, Kalb A, Yariv J. 1994. Structure of a unique twofold symmetric haem-binding site. Nat Struct Biol 453-460.

Gallagher KJ, Palasser M, Hughes S, Mackay CL, Kilgour DPA, Clarke DJ. 2020. Isotope Depletion Mass Spectrometry (ID-MS) for Accurate Mass Determination and Improved TopDown Sequence Coverage of Intact Proteins. J Am Soc Mass Spectrom 31:700-710. doi:10.1021/jasms.9b00119

Giessen TW, Orlando BJ, Verdegaal AA, Chambers MG, Gardener J, Bell DC, Birrane G, Liao M, Silver PA. 2019. Large protein organelles form a new iron sequestration system with high storage capacity. Elife 8. doi:10.7554/eLife.46070

Grant R, Filman D, Finkel S, Kolter R, Hogle J. 1998. The crystal structure of Dps, a ferritin homolog that binds and protects DNA. Nat Struct Biol 5:294-303.

Hagen W, Hagedoorn P-L, Ebrahimi K. 2017. The working of ferritin: a crossroad of options. Metallomics 9:595-605.

Hagen WR, Hagedoorn PL, Honarmand Ebrahimi K. 2017. The workings of ferritin: A crossroad of opinions. Metallomics. doi:10.1039/c7mt00124j

Hall Z, Hernández H, Marsh JA, Teichmann SA, Robinson C V. 2013. The Role of Salt Bridges, Charge Density, and Subunit Flexibility in Determining Disassembly Routes of Protein Complexes. Structure 21:1325-1337. doi:10.1016/j.str.2013.06.004

Harrison PM, Arosio P. 1996. The ferritins: molecular properties, iron storage function and cellular regulation. Biochim Biophys Acta - Bioenerg 1275:161-203. doi:10.1016/00052728(96)00022-9

He D, Hughes S, Vanden-Hehir S, Georgiev A, Altenbach K, Tarrant E, Mackay CL, Waldron KJ, Clarke DJ, Marles-Wright J. 2016. Structural characterization of encapsulated ferritin provides insight into iron storage in bacterial nanocompartments. Elife 5. doi:10.7554/eLife.18972

He D, Piergentili C, Ross J, Tarrant E, Tuck LR, Mackay CL, McIver Z, Waldron KJ, Clarke DJ, Marles-Wright J. 2019. Conservation of the structural and functional architecture of encapsulated ferritins in bacteria and archaea. Biochem J 476:975-989. doi:10.1042/bcj20180922

Hempstead PD, Hudson AJ, Artymiuk PJ, Andrews SC, Banfield MJ, Guest JR, Harrison PM. 1994. Direct observation of the iron binding sites in a ferritin. FEBS Lett 350:258-62. doi:10.1016/0014-5793(94)00781-0

Kabsch W. 2010. Integration, scaling, space-group assignment and post-refinement. Acta Crystallogr Sect D Biol Crystallogr 66:133-144. doi:10.1107/S0907444909047374

Karplus PA, Diederichs K. 2012. Linking Crystallographic Model and Data Quality. Science (80- ) 336:1030-1033. doi:10.1126/science.1218231 
842

843

844

845

846

847

848

849

850

851

852

853

854

855

856

857

858

859

860

861

862

863

864

865

866

867

868

869

870

871

872

873

874

875

876

877

878

879

880

881

882

883

884

885

886

887

888

889

890

891

892

Le Brun NE, Andrews SC, Guest JR, Harrison PM, Moore GR, Thomson AJ. 1995. Identification of the ferroxidase centre of Escherichia coli bacterioferritin. Biochem J 312:385-392. doi:10.1042/bj3120385

Liu XS, Patterson LD, Miller MJ, Theil EC. 2007. Peptides Selected for the Protein Nanocage Pores Change the Rate of Iron Recovery from the Ferritin Mineral. J Biol Chem 282:3182131825. doi:10.1074/jbc.C700153200

Marklund EG, Degiacomi MT, Robinson C V., Baldwin AJ, Benesch JLP. 2015. Collision Cross Sections for Structural Proteomics. Structure 23:791-799. doi:10.1016/j.str.2015.02.010

Martinez A, Kolter R. 1997. Protection of DNA during oxidative stress by the nonspecific DNAbinding protein Dps. J Bacteriol 179:5188-5194. doi:10.1128/JB.179.16.5188-5194.1997

Masuda T, Goto F, Yoshihara T, Mikami B. 2010. Crystal structure of plant ferritin reveals a novel metal binding site that functions as a transit site for metal transfer in ferritin. J Biol Chem. doi:10.1074/jbc.M109.059790

McCoy AJ, Grosse-Kunstleve RW, Adams PD, Winn MD, Storoni LC, Read RJ. 2007. Phaser crystallographic software. J Appl Crystallogr 40:658-674. doi:10.1107/S0021889807021206

Nair S, Finkel SE. 2004. Dps Protects Cells against Multiple Stresses during Stationary Phase. J Bacteriol 186:4192-4198. doi:10.1128/JB.186.13.4192-4198.2004

Pesek J, Büchler R, Albrecht R, Boland W, Zeth K. 2011. Structure and Mechanism of Iron Translocation by a Dps Protein from Microbacterium arborescens. J Biol Chem 286:3487234882. doi:10.1074/jbc.M111.246108

Pfaffen S, Abdulqadir R, Le Brun NE, Murphy MEP. 2013. Mechanism of Ferrous Iron Binding and Oxidation by Ferritin from a Pennate Diatom. J Biol Chem 288:14917-14925. doi:10.1074/jbc.M113.454496

Proulx-Curry PM, Chasteen ND. 1995. Molecular aspects of iron uptake and storage in ferritin. Coord Chem Rev 144:347-368. doi:10.1016/0010-8545(95)01148-I

Ratnayake DB, Wai SN, Shi Y, Amako K, Nakayama H, Nakayama K. 2000. Ferritin from the obligate anaerobe Porphyromonas gingivalis: purification, gene cloning and mutant studies The GenBank accession number for the sequence reported in this paper is AB016086. Microbiology 146:1119-1127. doi:10.1099/00221287-146-5-1119

Reyes-Caballero H, Campanello GC, Giedroc DP. 2011. Metalloregulatory proteins: Metal selectivity and allosteric switching. Biophys Chem 156:103-114. doi:10.1016/j.bpc.2011.03.010

Ross J, Lambert T, Piergentili C, He D, Waldron KJ, Mackay CL, Marles-Wright J, Clarke DJ. 2020. Mass spectrometry reveals the assembly pathway of encapsulated ferritins and highlights a dynamic ferroxidase interface. Chem Commun. doi:10.1039/C9CC08130E

Schägger H. 2006. Tricine-SDS-PAGE. Nat Protoc 1:16-22. doi:10.1038/nprot.2006.4

Stillman TJ, Hempstead PD, Artymiuk PJ, Andrews SC, Hudson AJ, Treffry A, Guest JR, Harrison PM. 2001. The high-resolution X-ray crystallographic structure of the ferritin (EcFtnA) of Escherichia coli; comparison with human $\mathrm{H}$ ferritin (HuHF) and the structures of the $\mathrm{Fe}(3+)$ and $\mathrm{Zn}(2+)$ derivatives. J Mol Biol 307:587-603. doi:10.1006/jmbi.2001.4475

Sztukowska M, Bugno M, Potempa J, Travis J, Kurtz Jr DM. 2002. Role of rubrerythrin in the oxidative stress response of Porphyromonas gingivalis. Mol Microbiol 44:479-488. doi:10.1046/j.1365-2958.2002.02892.x

Teale FWJ, Weber G. 1957. Ultraviolet fluorescence of the aromatic amino acids. Biochem J 65:476-482. doi:10.1042/bj0650476

Theil EC, Behera RK, Tosha T. 2013. Ferritins for chemistry and for life. Coord Chem Rev 257:579-586. doi:10.1016/j.ccr.2012.05.013

Tottey S, Waldron KJ, Firbank SJ, Reale B, Bessant C, Sato K, Cheek TR, Gray J, Banfield MJ, Dennison C, Robinson NJ. 2008. Protein-folding location can regulate manganese-binding versus copper- or zinc-binding. Nature 455:1138-1142. doi:10.1038/nature07340

Treffry A, Zhao Z, Quail MA, Guest JR, Harrison PM. 1998. How the presence of three iron 

binding sites affects the iron storage function of the ferritin $(\mathrm{EcFtnA})$ of Escherichia coli. FEBS Lett 432:213-218. doi:10.1016/S0014-5793(98)00867-9

895 Trefry A, Harrison PM. 1978. Incorporation and release of inorganic phosphate in horse spleen ferritin. Biochem J 171:313-320. doi:10.1042/bj1710313

$897 \mathrm{Xu}$ B, Chasteen N. 1991. Iron oxidation chemistry in ferritin. Increasing Fe/O2 stoichiometry during core formation. J Biol Chem 266:19965-70.

899

900

Yang X, Chen-Barrett Y, Arosio P, Chasteen ND. 1998. Reaction Paths of Iron Oxidation and

901

902

903

904 Hydrolysis in Horse Spleen and Recombinant Human Ferritins †. Biochemistry 37:9743-9750. doi:10.1021/bi973128a

Yao H, Wang Y, Lovell S, Kumar R, Ruvinsky AM, Battaile KP, Vakser IA, Rivera M. 2012. The Structure of the BfrB-Bfd Complex Reveals Protein-Protein Interactions Enabling Iron Release from Bacterioferritin. J Am Chem Soc 134:13470-13481. doi:10.1021/ja305180n

905

906 


\section{A}
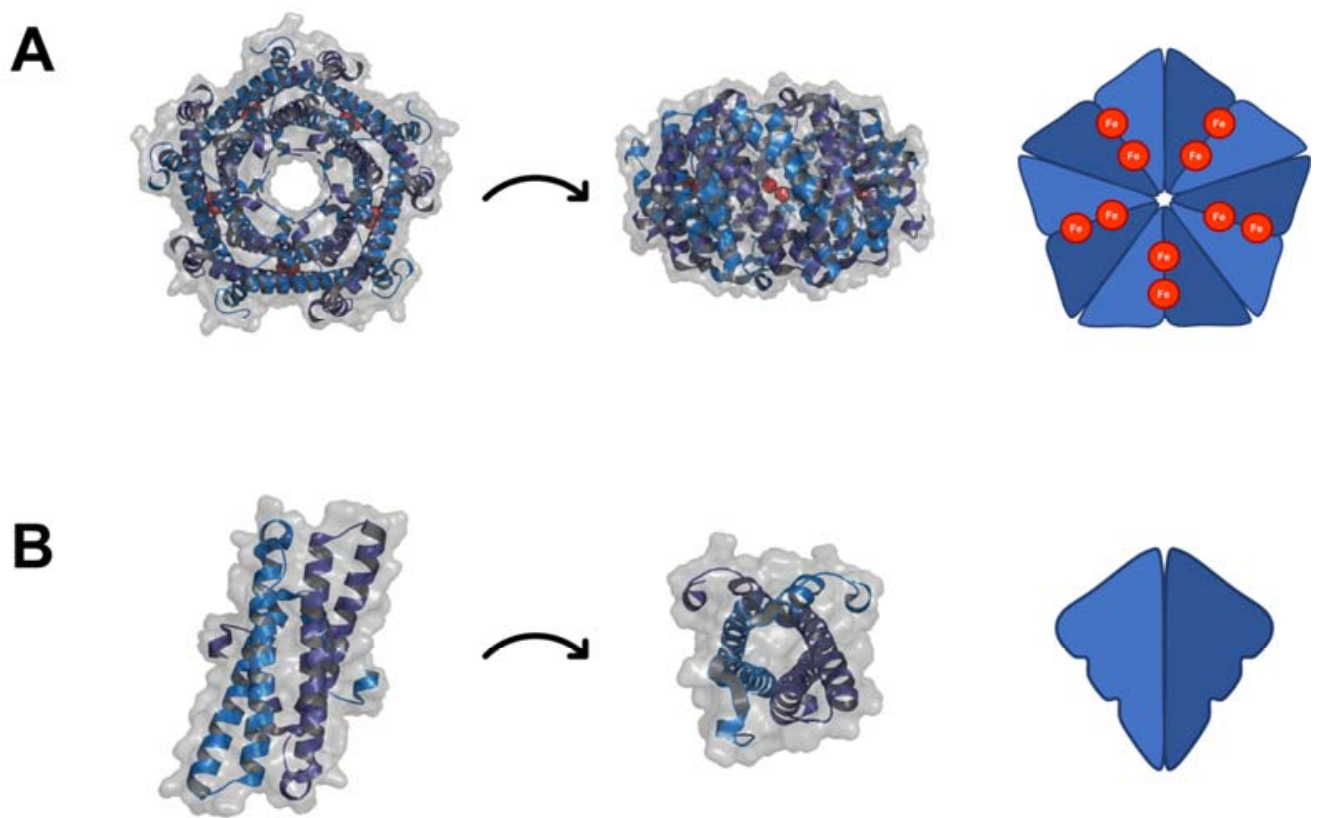

\section{Figure 1. EncFtn subcomplex architecture}

(A) Annular decamer structure of EncFtn shown with transparent solvent accessible surface rendered over cartoon secondary structure, with a simplified representation of topology. (B) The non-FOC dimer with cartoon secondary structure and transparent surface, and a simplified representation. (C) The non-FOC dimer in cartoon with two coordinated iron ions (shown as red spheres) and a simplified FOC cartoon is shown with two iron ions as red circles. 
916

917

918

919

920

921

922

923

924

925

926

927

928

929

930

931

932

933

934
A

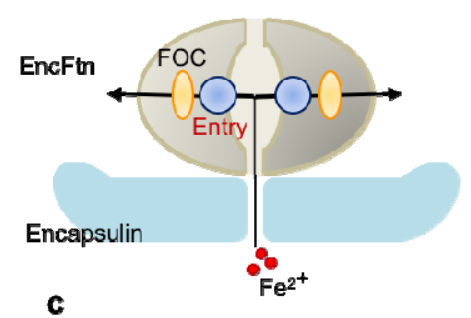

c
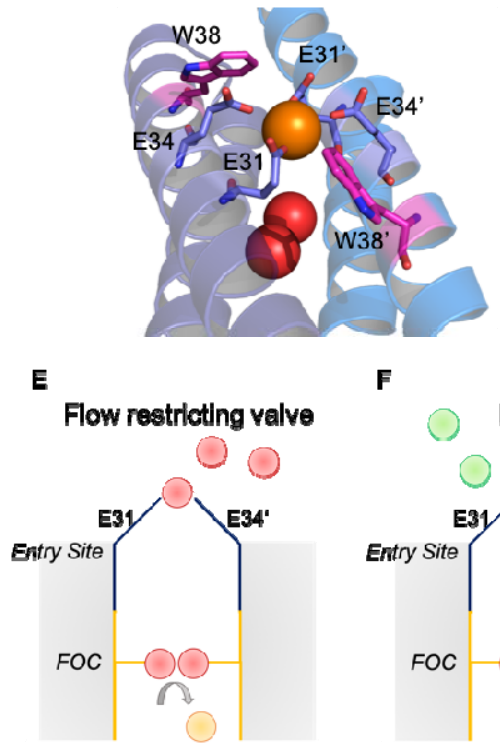

B

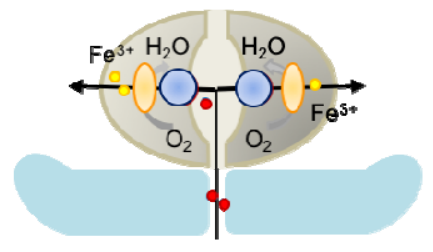

D

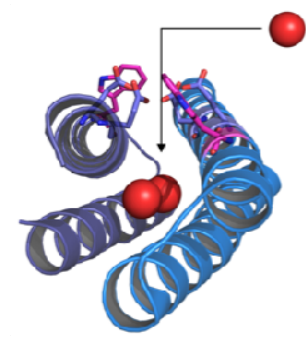

G

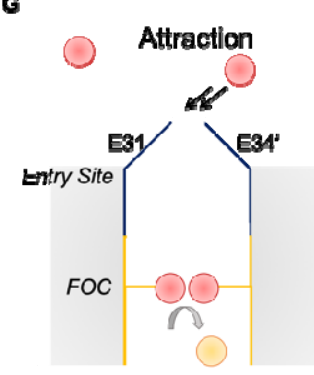

Figure 2. Hypotheses for the functional role of the entry site in EncFtn.

(A, B) Schematic view of the proposed pathway for incoming ferrous ions moving towards the ferroxidase center (FOC). EncFtn is represented by a grey oval, where the entry sites and ferroxidase centers are shown in blue and yellow, respectively. A portion of the encapsulin is displayed in pale blue, with emphasis given to the 5-fold pore used by ferrous ions to reach the encapsulated ferritin. Ferrous ions (red circles) are shown to be converted into ferric ions (yellow circles) in the ferroxidase center with the concomitant reduction of molecular oxygen. (C) Coordination of calcium (orange sphere) within the dimer interface by Glu31 and Glu34 from the two subunits. Iron ions coordinated in the ferroxidase center (FOC) are depicted as red spheres. Trp38 side chains (pink) from both chains are also shown. (D) Structure of the proposed iron entry site. The black arrow indicates movement of ferrous ions (red spheres) pathway to FOC through the EncFtn dimer interface. Glu31, Glu34 and Trp38 side chains from both subunits are shown.

Several hypotheses for the role played by the residues contributing to the entry site are shown in $\mathbf{E}$ $\mathbf{G}$ (flow restriction valve $(\mathbf{E})$, selectivity filter $(\mathbf{F})$, and attraction $(\mathbf{G})$. Ferrous and ferric ions are depicted as red and yellow circles, respectively, while non-cognate species are in green. The entry site and ferroxidase centrum locations are represented with blue and yellow lines, respectively. 


\section{EncFtn}

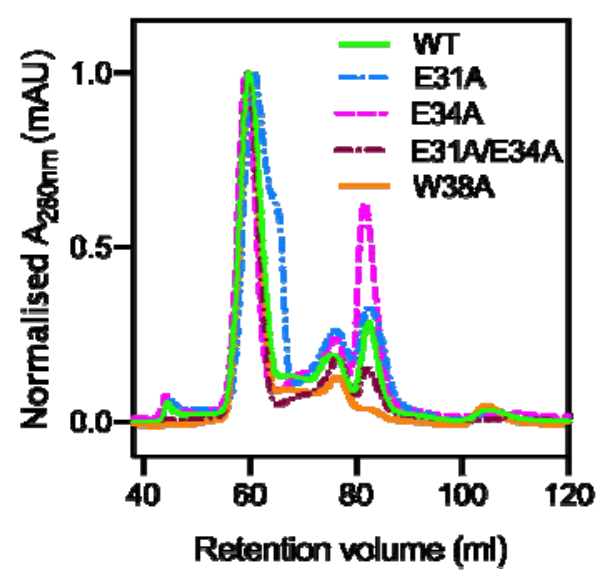

Enc:EncFtn

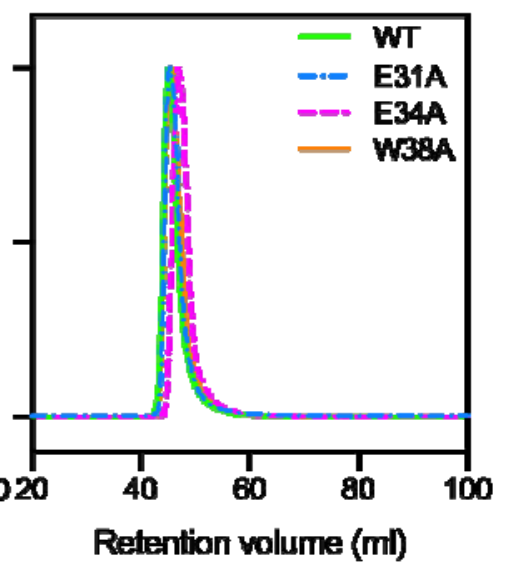

Figure 3. Purification of recombinant EncFtn and Enc:EncFtn protein complexes. Recombinant EncFtn (A) and Enc:EncFtn (B) proteins were purified by anion exchange chromatography (Hi-Trap Q-sepharose FF, GE Healthcare) and then subjected to size-exclusion chromatography using a Superdex 200 16/60 column (GE Healthcare) previously equilibrated with $50 \mathrm{mM}$ Tris- $\mathrm{HCl}, \mathrm{pH} 8.0,150 \mathrm{mM} \mathrm{NaCl}$. The elution profiles in A reveal that all EncFtn proteins show a main peak at around $60 \mathrm{ml}$, diagnostic of oligomerization states close to 10-mer, and smaller peaks at $\sim 76 \mathrm{ml}$ and $82 \mathrm{ml}$ (indicative of smaller assembly states, Table 2). Enc:EncFtn proteins elute in a single peak around $46 \mathrm{ml}$, suggesting that EncFtn is compartmentalized within the Encapsulin shell. An SDS-PAGE gel of (B) is shown in Figure 3-figure supplement 1, while transmission electron micrographs of Enc:EncFtn proteins are presented in Figure 3-supplement 2. Comparison of elution profiles from gel-filtration purification step of EncFtn-W38A and W38G are shown in Figure 3-figure supplement 3A/B. doi. 10.6084/m9.figshare.9885557 
951

952

953

954

955

956

957

958

959

960

961

962

963

964
Figure 4. Comparison of metal ion binding in EncFtn entry site variant crystal.

Metal ion entry sites for the X-ray crystal structures of the E31A and E34A EncFtn variants are shown with the EncFtn-sH wild-type for comparison. Residues in the entry site are shown as stick representations with spheres for coordinated calcium ions. Residues in the entry site are labelled, with residues from the second monomer indicated with prime symbols. WT is shown in grey, with the coordinated calcium ion in grey with coordination distances shown. E31A is shown in green with coordinated calcium ion in green; the metal ion is further from the site in this variant, with coordination distances to Glu34 of $3.8 \AA$. The E34A variant is shown in blue; no metal is coordinated in this site, and in the absence of a metal ion Glu31 is shifted by $117^{\circ}$ when compared to the WT. Experimental electron density maps for the entry site residues of the E31A and E34 variants are shown in Figure-4-figure supplements 1 and 2 respectively. 
965

966

967

968

969

970

971

972

973

974

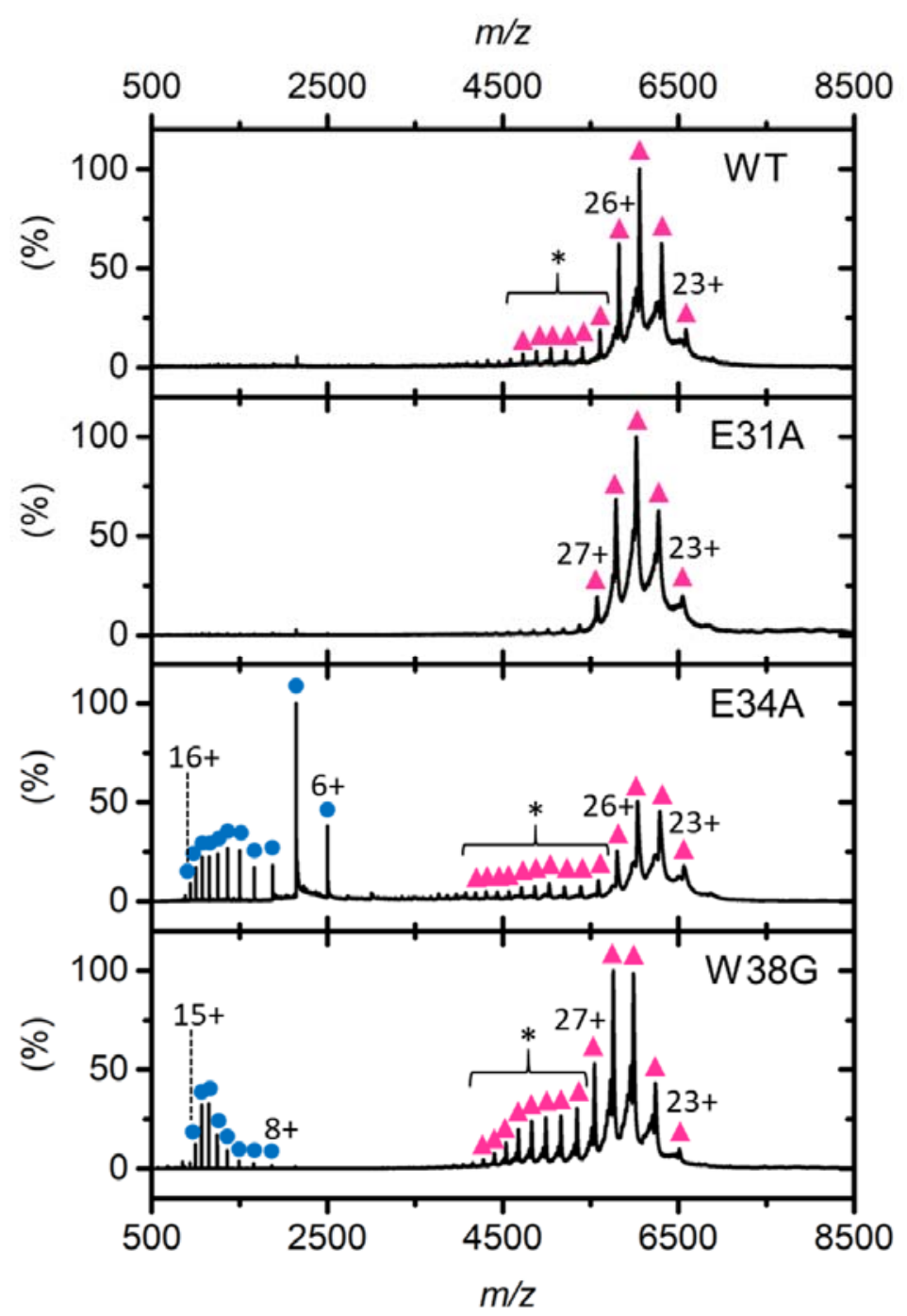

\section{Figure 5. Native MS Analysis of EncFtn variants.}

Native nESI spectra of EncFtn variants displaying decameric (pink triangles) and monomeric (blue circles) charge state distributions. The elongated decameric charge state distributions of WT and E34A are highlighted by an asterisk. Gas phase dissociation of each variant is shown in Figure 7figure supplement 1. Collision induced unfolding (CIU) MS experiments are presented as heat maps in Figure 7-figure supplement 2, with comparison of the relative ratio of compact to extended forms of each variant in Figure 7-figure supplement 3. 


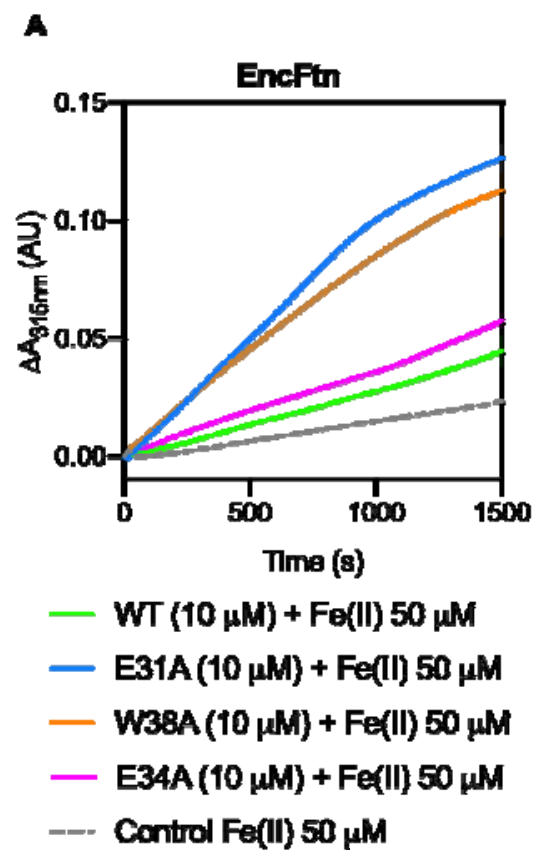

B

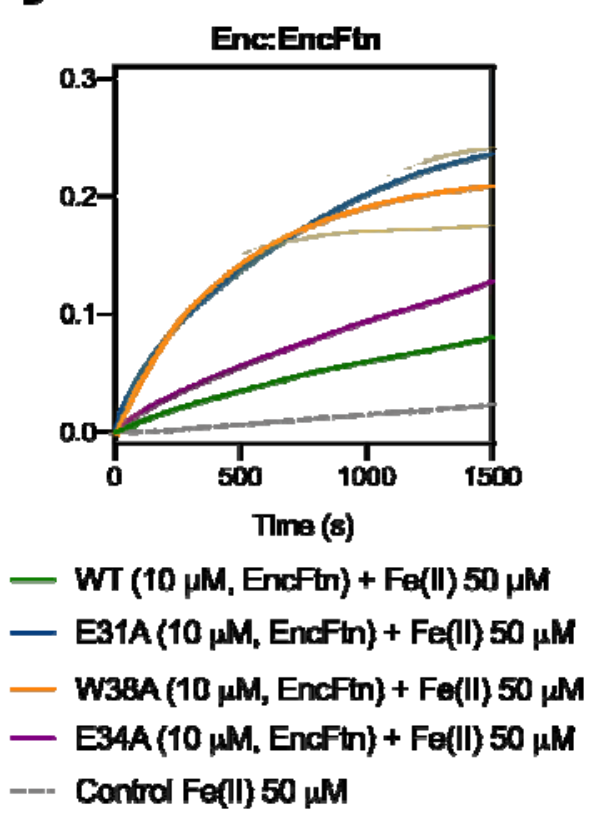

Figure 6. Ferroxidase activity of EncFtn and Enc:EncFtn complexes.

(A) EncFtn wild-type (green line), EncFtn-E34A (pink line), EncFtn-E31A (blue line), and EncFtnW38A (orange line), $\left(10 \mu \mathrm{M}\right.$, monomer) were incubated with $50 \mu \mathrm{M} \mathrm{FeSO}_{4} .7 \mathrm{H}_{2} \mathrm{O}$ (10 times molar equivalent $\mathrm{Fe}$ (II) per FOC) and progress curves of the oxidation of $\mathrm{Fe}$ (II) to $\mathrm{Fe}$ (III) was monitored at $315 \mathrm{~nm}$ at room temperature. The background oxidation of iron at $50 \mu \mathrm{M}$ in enzyme-free control is shown for reference (dotted grey line). Solid lines represent the average $(n=3)$ of technical replicates, shaded areas represent standard deviation from the mean. Protein and iron samples were prepared anaerobically in Buffer $\mathrm{H}(10 \mathrm{mM}$ HEPES pH 8.0, $150 \mathrm{mM} \mathrm{NaCl})$, and $0.1 \%$ (v/v) $\mathrm{HCl}$, respectively. (B) Enc:EncFtn-WT (dark green line), Enc:EncFtn-E34A (dark pink line), Enc:EncFtn-E31A (dark blue line), and Enc:EncFtn-W38A (orange line) (25 $\mu \mathrm{M}$ Enc:EncFtn, corresponding to $10 \mu \mathrm{M}$ EncFtn monomer) were incubated with $50 \mu \mathrm{M} \mathrm{FeSO} 4.7 \mathrm{H}_{2} \mathrm{O}$ and progress curves of the oxidation of $\mathrm{Fe}$ (II) to $\mathrm{Fe}$ (III) was monitored at $315 \mathrm{~nm}$ at room temperature. The background oxidation of iron at $50 \mu \mathrm{M}$ in enzyme-free control is shown for reference (dotted grey line). Solid lines represent the average $(n=3)$ of technical replicates, shaded areas represent standard deviation from the mean. Protein and iron samples were prepared anaerobically in Buffer $\mathrm{H}(10 \mathrm{mM}$ HEPES pH 8.0, $150 \mathrm{mM} \mathrm{NaCl})$, and $0.1 \%$ (v/v) $\mathrm{HCl}$, respectively.

Comparison of data collected for W38A and W38G variants are shown in Figure 3-figure supplement 3, including elution profiles from gel-filtration purification steps (A/B), ferroxidase activities of Enc:EncFtn-W38A and W38G (C) and Enc:EncFtn-W38A and W38G transmission electron micrographs (D/E). Data shown in A and B were re-plotted together in Figure 6-figure supplement 1 to emphasize the increase in activity when EncFtn are encapsulated. Linear regression on first 200s of ferroxidase assays with EncFtn and Enc:EncFtn proteins is shown in Figure 6-figure supplement 2, while Figure 6-figure supplement 3 presents comparison between EncFtn-E34A and E31A/E34A catalytic activities. doi.10.6084/m9.figshare. 9885575 
1005

1006

1007

1008

1009

1010

1011

1012

1013

1014

1015

1016

1017

1018
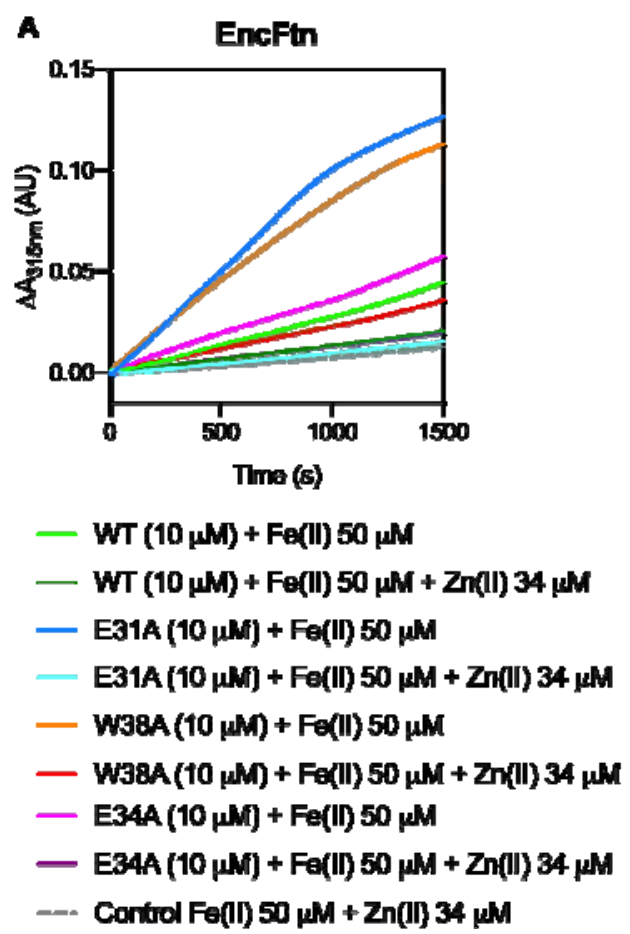
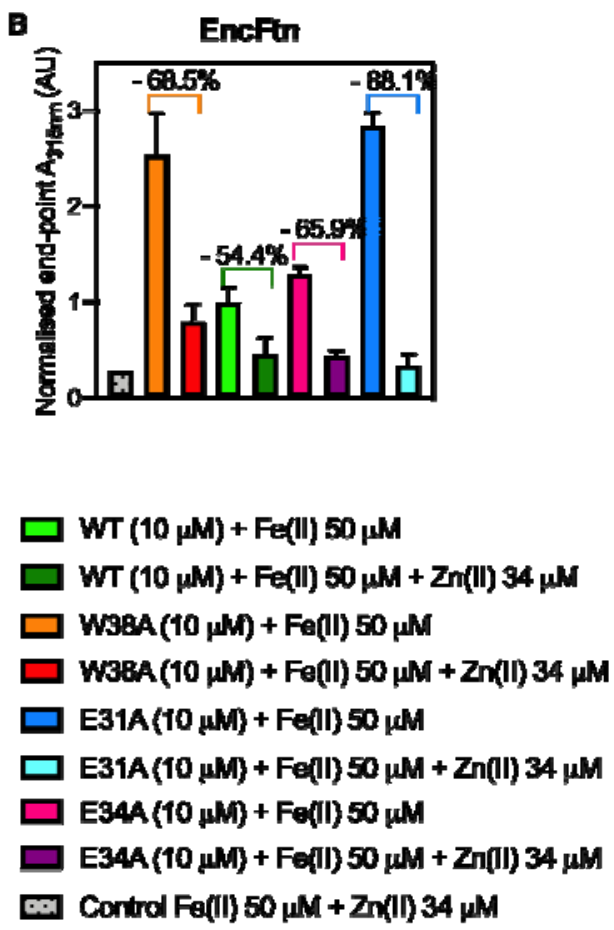

Figure 7. Ferroxidase activity of EncFtn wild-type and variants is inhibited by zinc.

(A) Comparison between data shown in Figure 6A, collected in the absence of competing metals, are here plotted with curves from ferroxidase assays of EncFtn wild-type and variants carried out using [protein $]=10 \mu \mathrm{M}$ and $[\mathrm{Fe}(\mathrm{II})]=50 \mu \mathrm{M}$ in the presence of $[\mathrm{Zn}(\mathrm{II})]=34 \mu \mathrm{M}$. The zinc concentration corresponds to a response inhibited by $50 \%$ for EncFtn-Strep under the same experimental conditions (He et al., 2019). EncFtn wild-type is represented by a dark green line, EncFtn-E34A by a purple line, EncFtn-E31A by a pale blue line, and EncFtn-W38A by a red line. As a control, a mix of $\mathrm{Fe}$ (II) and $\mathrm{Zn}$ (II) salts (grey dotted line) were assayed in the absence of the enzyme. (B) End-point data presented in Figure 7A were plotted as columns to compare inhibition by zinc. Percentage of inhibition is shown above corresponding columns. Color-coding is consistent with Figure 7A. doi.10.6084/m9.figshare.9885575 
A

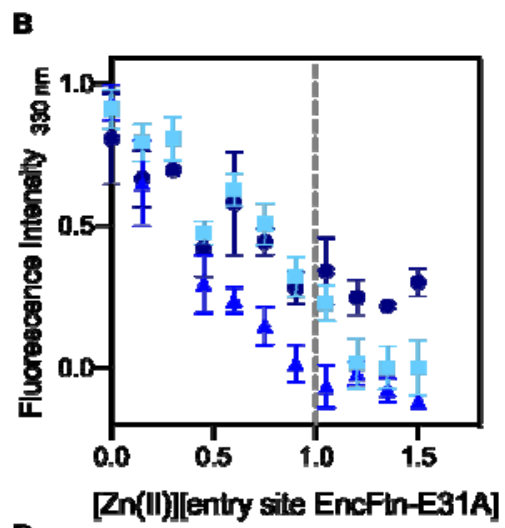

c

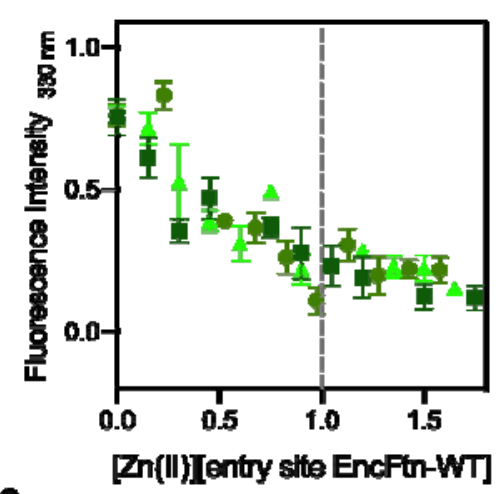

D

Zn(II)][entry site EncFin-E31A]
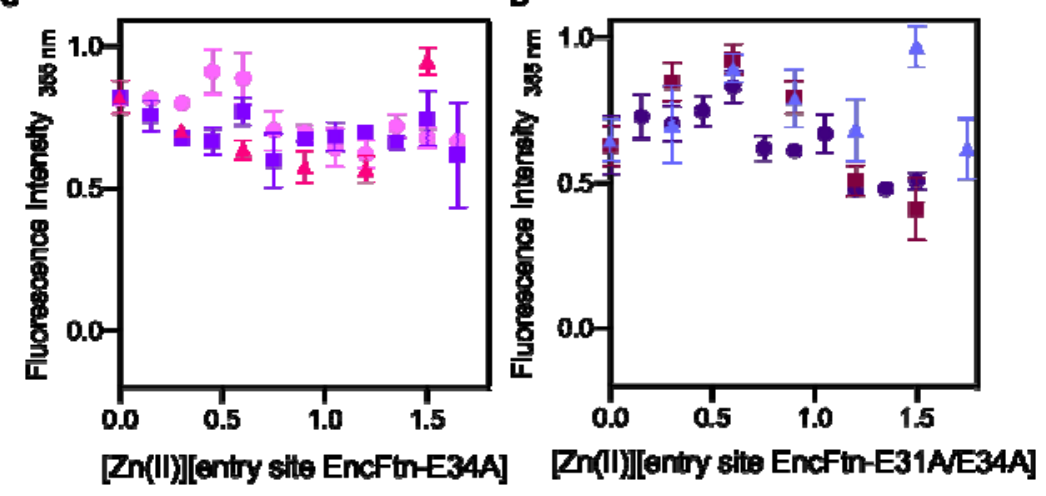

E

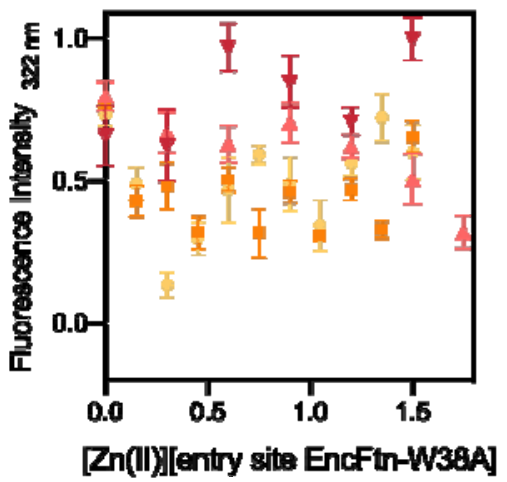

Figure 8. Intrinsic fluorescence of EncFtn wild-type and variants titrated with $\mathrm{Zn}$ (II). Fluorescence emission of EncFtn proteins $(20 \mu \mathrm{M}$, corresponding to [entry-site] $=10 \mu \mathrm{M})$ at various wavelength (330 $\mathrm{nm}$ for EncFtn-WT and -E31A, $355 \mathrm{~nm}$ for EncFtn-E34A and E31A/E34A, and $322 \mathrm{~nm}$ for EncFtn-W38A) with excitation at $280 \mathrm{~nm}$, and following titration with $\mathrm{ZnSO}_{4} .7 \mathrm{H}_{2} \mathrm{O}$. (A/B) Fluorescence is quenched upon zinc addition, with inflection around 1 molar equivalents, suggesting perturbation of environment around $\operatorname{Trp} 38$. (C/D) In the absence of entry site residues available for metal coordination no quenching was observed. (E) EncFtn-W38A was tested as control. Symbols represent average and standard deviation of experimental replicates, collected at equilibrium either by Scan $(n>3)$ or Kinetic $(n=10)$ options on the Cary Eclipse software package. Dotted grey lines were added at 1 molar equivalent of $\mathrm{Zn}$ (II) when inflection was observed. Intrinsic tryptophan fluorescence emission spectra in the absence of $\mathrm{Zn}$ (II) of wild-type and variants are shown in Figure 8-figure supplement 1 to display maximum emission values. Figure 8-figure supplement 2 shows fluorescence spectra in the presence and absence of 1.5 molar 


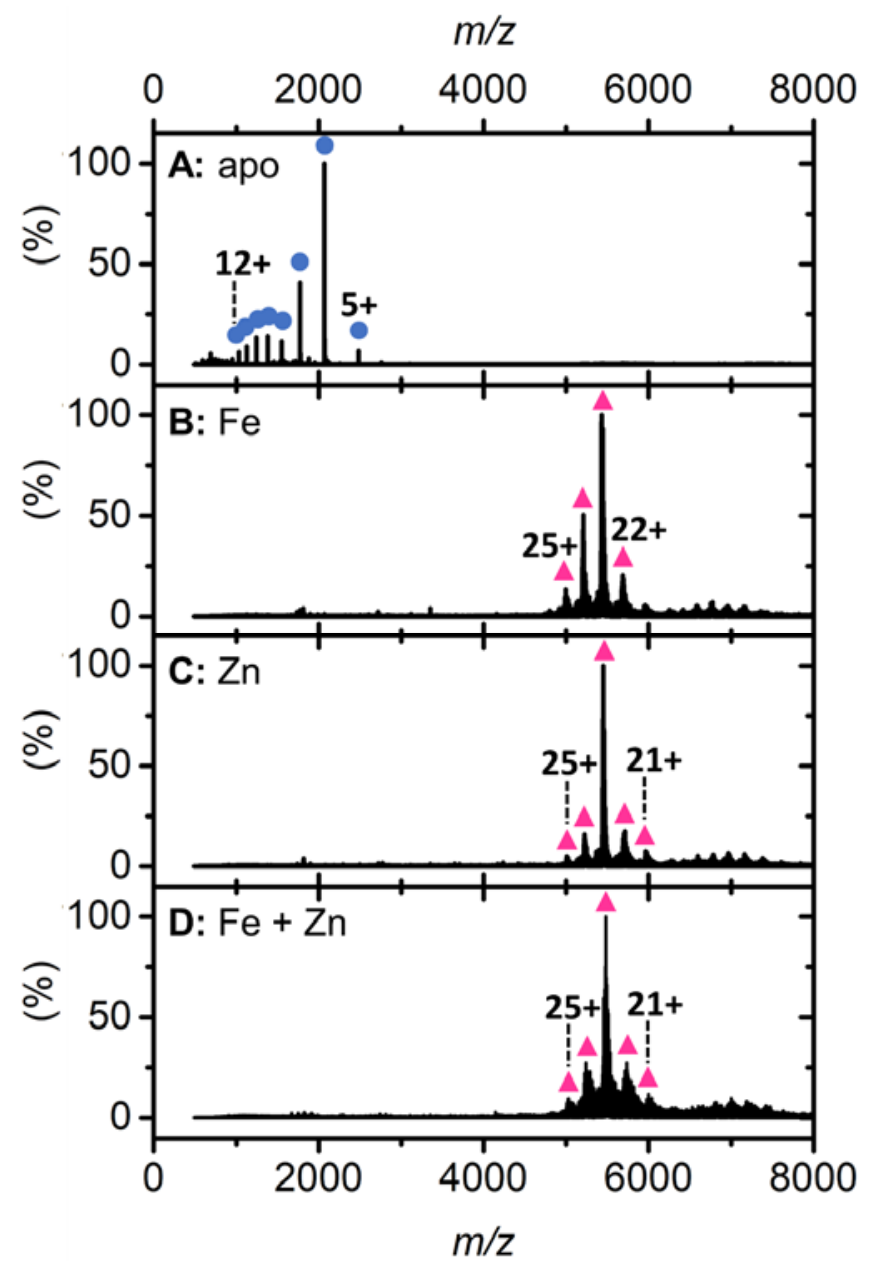

Figure 9. Native FT-ICR mass spectrum of $I D$-EncFtn

Native nESI mass spectra of: apo-ID-EncFtn (A); ID-EncFtn titrated with Fe(II) (B); ID-EncFtn titrated with $\mathrm{Zn}$ (II) (C); and ID-EncFtn titrated with Fe(II) followed by $\mathrm{Zn}$ (II) (D). Oligomerization states are stressed with colored shapes, monomer in blue circles and decamer in pink triangles. Metal loading of (A) is shown in Figure 9-figure supplement 1, and metal association of B-D is shown in Figure 9-figure supplement 2. B, C and D experience different dissociation pathways during CID shown in Figure 9-figure supplement 3, Figure 9-figure supplement 4 and Figure 9figure supplement 5 respectively. 
Table 1. Average molecular masses of encapsulated ferritins obtained by LC-MS.

\begin{tabular}{|c|c|c|c|}
\hline Protein & Observed Mass (Da) & Assignment & Theoretical Mass (Da) \\
\hline \multirow{2}{*}{ EncFtn-WT } & $15060.71 \pm 0.14$ & monomer without Met & 15061.55 \\
\cline { 2 - 4 } & $30120.78 \pm 0.48$ & dimer without Met & 30123.10 \\
\hline EncFtn-E31A & $15003.78 \pm 0.03$ & monomer without Met & 15003.51 \\
\hline \multirow{2}{*}{ EncFtn-E34A } & $15003.29 \pm 0.07$ & monomer without Met & 15003.51 \\
\cline { 2 - 4 } & $30006.20 \pm 0.84$ & dimer without Met & 30007.02 \\
\hline EncFtn-W38A & $14946.09 \pm 0.08$ & monomer without Met & 14946.42 \\
\hline EncFtn-W38G & $14932.33 \pm 0.06$ & monomer without Met & 14932.39 \\
\hline \multirow{3}{*}{ Enc:EncFtn-WT } & $29733.06 \pm 0.16$ & Enc monomer with Met & 29732.99 \\
\cline { 2 - 4 } & $15061.59 \pm 0.15$ & EncFtn monomer without Met & 15061.55 \\
\cline { 2 - 4 } Enc:EncFtn-E31A & $30121.88 \pm 0.78$ & EncFtn dimer without Met & 30123.10 \\
\cline { 2 - 4 } & $29732.42 \pm 0.09$ & Enc monomer with Met & 29732.99 \\
\hline \multirow{3}{*}{ Enc:EncFtn-E34A } & $15003.59 \pm 0.14$ & E31A monomer without Met & 15003.51 \\
\cline { 2 - 4 } & $29732.80 \pm 0.22$ & Enc monomer with Met & 29732.99 \\
\cline { 2 - 4 } & $15003.05 \pm 0.25$ & E34A monomer without Met & 15003.51 \\
\hline \multirow{2}{*}{ Enc:EncFtn-W38A } & $29005.48 \pm 0.95$ & E34A dimer without Met & 30007.02 \\
\cline { 2 - 4 } & $14946.87 \pm 0.25 \pm 0.04$ & Enc monomer with Met & 29732.99 \\
\hline \multirow{2}{*}{ Enc:EncFtn-W38G } & $29732.37 \pm 0.46$ & W38A monomer without Met & 14946.42 \\
\cline { 2 - 4 } & $14932.23 \pm 0.06$ & W38G monomer with Met & 29732.99 \\
\hline ID-EncFtn & $12404.67 \pm 0.06$ & monomer without Met & 124932.39 \\
\hline
\end{tabular}

1047 The starting Methionine residue is not always retained, and this has been indicated in "Assignment". Error 1048 values generated from MassLynx v4.1. 
bioRxiv preprint doi: https://doi.org/10.1101/785121; this version posted April 28, 2020. The copyright holder for this preprint (which was not certified by peer review) is the author/funder. All rights reserved. No reuse allowed without permission.

Table 2. Elution volumes and oligomerization states of EncFtn and Enc:EncFtn from size-exclusion chromatography.

\begin{tabular}{|c|c|c|c|c|c|c|c|}
\hline Protein & Theoretical Mass & & k 1 & & & & k 3 \\
\hline EncFtn & 15061.55 & $\begin{array}{l}\mathrm{V}_{\mathrm{e}}= \\
59.89 \mathrm{ml}\end{array}$ & $\begin{array}{l}292 \mathrm{kDa} \\
19-\mathrm{mer}\end{array}$ & $\begin{array}{l}\mathrm{V}_{\mathrm{e}}= \\
75.68 \mathrm{ml}\end{array}$ & $\begin{array}{l}81 \mathrm{kDa} \\
5-\mathrm{mer}\end{array}$ & $\begin{array}{l}\mathrm{V}_{\mathrm{e}}= \\
82.38 \mathrm{ml}\end{array}$ & $\begin{array}{l}47 \mathrm{kDa} \\
\text { 3-mer }\end{array}$ \\
\hline EncFtn-E31A & 15003.51 & $\begin{array}{l}\mathrm{V}_{\mathrm{e}}= \\
60.77 \mathrm{ml}\end{array}$ & $\begin{array}{l}272 \mathrm{kDa} \\
18-\mathrm{mer}\end{array}$ & $\begin{array}{l}\mathrm{V}_{\mathrm{e}}= \\
76.15 \mathrm{ml}\end{array}$ & $\begin{array}{l}78 \mathrm{kDa} \\
5-\mathrm{mer}\end{array}$ & $\begin{array}{l}\mathrm{V}_{\mathrm{e}}= \\
82.53 \mathrm{ml}\end{array}$ & $\begin{array}{l}46 \mathrm{kDa} \\
\text { 3-mer }\end{array}$ \\
\hline EncFtn-E34A & 15003.51 & $\begin{array}{l}\mathrm{V}_{\mathrm{e}}= \\
59.42 \mathrm{ml}\end{array}$ & $\begin{array}{l}304 \mathrm{kDa} \\
20-\mathrm{mer}\end{array}$ & $\begin{array}{l}\mathrm{V}_{\mathrm{e}}= \\
76.01 \mathrm{ml}\end{array}$ & $\begin{array}{l}79 \mathrm{kDa} \\
5 \text {-mer }\end{array}$ & $\begin{array}{l}\mathrm{V}_{\mathrm{e}}= \\
81.63 \mathrm{ml}\end{array}$ & $\begin{array}{l}50 \mathrm{kDa} \\
\text { 3-mer }\end{array}$ \\
\hline EncFtn-W38A & 14946.42 & $\begin{array}{l}\mathrm{V}_{\mathrm{e}}= \\
59.94 \mathrm{ml}\end{array}$ & $\begin{array}{l}291 \mathrm{kDa} \\
19-\mathrm{mer}\end{array}$ & $\begin{array}{l}\mathrm{V}_{\mathrm{e}}= \\
76.48 \mathrm{ml}\end{array}$ & $\begin{array}{l}76 \mathrm{kDa} \\
5-\mathrm{mer}\end{array}$ & & \\
\hline EncFtn-W38G & 14932.39 & $\begin{array}{l}\mathrm{V}_{\mathrm{e}}= \\
60.07 \mathrm{ml}\end{array}$ & $\begin{array}{l}288 \mathrm{kDa} \\
19-\mathrm{mer}\end{array}$ & $\begin{array}{l}\mathrm{V}_{\mathrm{e}}= \\
75.45 \mathrm{ml}\end{array}$ & $\begin{array}{l}82 \mathrm{kDa} \\
5-\mathrm{mer}\end{array}$ & $\begin{array}{l}\mathrm{V}_{\mathrm{e}}= \\
82.59 \mathrm{ml}\end{array}$ & $\begin{array}{l}46 \mathrm{kDa} \\
\text { 3-mer }\end{array}$ \\
\hline Enc-EncFtn & & $\begin{array}{l}\mathrm{V}_{\mathrm{e}}= \\
45.18 \mathrm{ml}\end{array}$ & $966 \mathrm{kDa}$ & & & & \\
\hline $\begin{array}{l}\text { Enc:EncFtn- } \\
\text { E31A }\end{array}$ & & $\begin{array}{l}\mathrm{V}_{\mathrm{e}}= \\
45.32 \mathrm{ml}\end{array}$ & $955 \mathrm{kDa}$ & & & & \\
\hline $\begin{array}{l}\text { Enc:EncFtn- } \\
\text { E34A }\end{array}$ & & $\begin{array}{l}\mathrm{V}_{\mathrm{e}}= \\
46.91 \mathrm{ml}\end{array}$ & $839 \mathrm{kDa}$ & & & & \\
\hline $\begin{array}{l}\text { Enc:EncFtn- } \\
\text { W38A }\end{array}$ & & $\begin{array}{l}\mathrm{V}_{\mathrm{e}}= \\
45.42 \mathrm{ml}\end{array}$ & $947 \mathrm{kDa}$ & & & & \\
\hline $\begin{array}{l}\text { Enc:EncFtn- } \\
\text { W38G }\end{array}$ & & $\begin{array}{l}\mathrm{V}_{\mathrm{e}}= \\
46.92 \mathrm{ml}\end{array}$ & 839 kDa & & & & \\
\hline
\end{tabular}

Oligomerization states of EncFtn proteins were calculated from comparison of experimental molecular masses, calculated by elution volume $\left(\mathrm{V}_{\mathrm{e}}\right)$ values for each peak observed in $\mathrm{S} 200$ size-exclusion chromatography elution profile curves (Figure 3), with theoretical masses (without Met1). A GE Healthcare S200 16/60 column was calibrated using GE Healthcare Gel filtration calibration kits (LMW/HMW). However, previous work conducted on representative members of the EncFtn family (Ross et al., 2020, He et al., 2019) suggests that peaks 1, 2, and 3 would correspond to decamer, tetramer, and dimer species, respectively. Presumably, the presence of the flexible encapsulation sequence in full length EncFtn proteins results in a considerable increase of the hydrodynamic radius of the oligomers. 
1063 Table 3. Collision cross sections (CCS) of the compact and extended conformations of the EncFtn 1064 variants

\begin{tabular}{|c|c|c|c|}
\hline Protein & $\begin{array}{c}\text { Theoretical CCS } \\
\left(\mathbf{n m}^{\mathbf{2}}\right)^{\star}\end{array}$ & $\begin{array}{c}\text { Observed Compact } \\
\mathbf{C C S}\left(\mathbf{n m}^{\mathbf{2}}\right)\end{array}$ & $\begin{array}{c}\text { Observed Extended } \\
\mathbf{C C S}\left(\mathbf{n m}^{\mathbf{2}}\right)\end{array}$ \\
\hline EncFtn-WT & 58.7 & 71.40 & 80.62 \\
\hline EncFtn-E31A & 58.3 & 69.50 & 82.65 \\
\hline EncFtn-E34A & 58.4 & 71.30 & 81.68 \\
\hline EncFtn-W38G & - & 71.17 & 81.41 \\
\hline
\end{tabular}

1065

CCS values were calculated using DriftScope v2.5.

$1066 *$ Theoretical CCS were calculated based on the truncated sHis crystal structures using IMPACT software

1067 
1068 Table 4. Linear regression fit of EncFtn ferroxidase assay progress curves.

\begin{tabular}{|l|l|l|l|l|}
\hline & EncFtn-WT & EncFtn-E31A & EncFtn-W38A & EncFtn-E34A \\
\hline Equation & $\mathrm{Y}=2.322 \mathrm{e}-005^{\star} \mathrm{X}-$ & $\begin{array}{l}\mathrm{Y}=0.0001012^{\star} \mathrm{X}- \\
0.001880\end{array}$ & $\begin{array}{l}\mathrm{Y}=9.463 \mathrm{e}-005^{\star} \mathrm{X}+ \\
0.0004715\end{array}$ & $\begin{array}{l}\mathrm{Y}=4.378 \mathrm{e}-005^{\star} \mathrm{X}- \\
0.0002987\end{array}$ \\
\hline Slope $m$ & 2.0001751 & & & \\
\hline $\begin{array}{l}2.522 \mathrm{e}-005 \pm \\
2.510 \mathrm{e}-007\end{array}$ & $\begin{array}{l}0.0001012 \pm \\
3.109 \mathrm{e}-007\end{array}$ & $\begin{array}{l}9.463 \mathrm{e}-005 \pm \\
1.575 \mathrm{e}-007\end{array}$ & $\begin{array}{l}4.378 \mathrm{e}-005 \pm \\
1.339 \mathrm{e}-007\end{array}$ \\
\hline $\begin{array}{l}\text { square } \\
\begin{array}{l}\text { Number } \mathrm{X} \\
\text { values }\end{array}\end{array}$ & 0.9773 & 0.9981 & 0.9994 & 0.9981 \\
\hline
\end{tabular}

1069 Equation values from linear regression curves calculated on data from first $200 \mathrm{~s}$ of ferroxidase assay carried

1070 out with EncFtn proteins (Figures 9A, 10A). Slope values correspond to $v_{0}$, initial enzymatic rates, as

1071 reaction follows zero order catalysis. doi10.6084/m9.figshare. 9885575

1072 
Table 5. Linear regression fit data of Enc:EncFtn ferroxidase assay progress curves.

\begin{tabular}{|l|l|l|l|l|}
\hline & Enc:EncFtn-WT & Enc:EncFtn-E31A & Enc:EncFtn-W38A & Enc:EncFtn-E34A \\
\hline Equation & $\begin{array}{l}\mathrm{Y}=8.658 \mathrm{e}-005^{\star} \mathrm{X}- \\
0.0004506\end{array}$ & $\begin{array}{l}\mathrm{Y}=0.0003718^{\star} \mathrm{X}+ \\
0.007998\end{array}$ & $\begin{array}{l}\mathrm{Y}=0.0004038^{\star} \mathrm{X}- \\
0.0009754\end{array}$ & $\begin{array}{l}\mathrm{Y}=0.0001323^{\star} \mathrm{X}+ \\
0.002270\end{array}$ \\
& & & & \\
\hline Slope $m$ & $\begin{array}{l}8.658 \mathrm{e}-005 \pm \\
3.470 \mathrm{e}-007\end{array}$ & $0.0003718 \pm$ & $0.0004038 \pm$ & $0.0001323 \pm$ \\
& $3.233 \mathrm{e}-006$ & $1.581 \mathrm{e}-006$ & $5.404 \mathrm{e}-007$ \\
\hline R square & 0.9968 & 0.9852 & 0.997 & 0.9967 \\
\hline $\begin{array}{l}\text { Number } \\
\text { of } \mathrm{X}\end{array}$ & 201 & 201 & 201 & 201 \\
values & & & & \\
\hline
\end{tabular}

1074 Equation values from linear regression curves calculated on data from first $200 \mathrm{~s}$ of ferroxidase assay carried

1075 out with Enc:EncFtn proteins (Figures 9B, 10B). Slope values correspond to $v_{0}$, initial enzymatic rates, as

1076 reaction follows zero order catalysis. doi10.6084/m9.figshare. 9885575

1077 
1078 Table 6. EncFtn variants initial enzymatic rate ratios.

\begin{tabular}{|c|c|c|c|}
\hline & E31A & W38A & E34A \\
\hline $\begin{array}{l}\text { EncFtn } \\
v_{0}{ }^{\text {variant }} / v_{0} \text { wild-type }\end{array}$ & 4.36 & 4.08 & 1.89 \\
\hline $\begin{array}{l}\text { Enc:EncFtn } \\
v_{0}{ }^{\text {variant }} / v_{0} \text { wild-type }\end{array}$ & 4.30 & 4.66 & 1.53 \\
\hline
\end{tabular}

1079 The initial enzymatic rates of the variants $\left(v_{0}{ }^{\text {variant }}\right)$ were divided by the initial rate $v_{0}{ }^{\text {wild-type }}$. Initial rates were calculated on data from the first $200 \mathrm{~s}$ of ferroxidase assays (Tables 4 and 5).

1081 The resulting values allow comparison between enzymatic kinetics of EncFtn and Enc:EncFtn proteins.

1082 doi10.6084/m9.figshare. 9885575

1083 
bioRxiv preprint doi: https://doi.org/10.1101/785121; this version posted April 28, 2020. The copyright holder for this preprint (which was not certified by peer review) is the author/funder. All rights reserved. No reuse allowed without permission.

1084

Table 7. Protein nomenclature

\begin{tabular}{|c|c|}
\hline Protein & Alternative nomenclature \\
\hline Wild type EncFtn & EncFtn-WT \\
\cline { 2 - 2 } E31A variant of EncFtn-WT & WT \\
\hline \multirow{2}{*}{ E34A variant of EncFtn-WT } & E31A \\
\cline { 2 - 2 } W38A variant of EncFtn-WT & EncFtn-E34A \\
\cline { 2 - 2 } W38G variant of EncFtn-WT & EncFtn-W38A \\
\hline \multirow{2}{*}{ E31A and E34A double variant of EncFtn-WT } & W38A \\
\hline \multirow{2}{*}{ Wild type Enc and EncFtn complex } & W38G \\
\hline \multirow{2}{*}{ Wild type Enc and E31A variant of EncFtn complex } & EncFtn-E31A/E34A \\
\hline \multirow{2}{*}{ Wild type Enc and E34A variant of EncFtn complex } & E31A/E34A \\
\hline \multirow{2}{*}{ Wild type Enc and W38A variant of EncFtn complex } & WT \\
\hline \multirow{2}{*}{ Wild type Enc and W38G variant of EncFtn complex } & Enc:EncFtn-E31A \\
\cline { 2 - 2 } His-tagged version & E31A \\
\hline Strepll-tagged version & E34A \\
\hline Isotopically depleted version & Enc:EncFtn-W38A \\
\hline
\end{tabular}

1085 Nomenclature adopted throughout this work to refer to the same species. The above is valid for each variant used in the study. When referring to tagged versions, the protein name acquires the specific suffix. 
bioRxiv preprint doi: https://doi.org/10.1101/785121; this version posted April 28, 2020. The copyright holder for this preprint (which was not certified by peer review) is the author/funder. All rights reserved. No reuse allowed without permission.

1088 Table 8. Primers used in this study.

\begin{tabular}{|l|l|l|}
\hline Construct & Forward SDM Primer & Reverse SDM Primer \\
\hline EncFtn-E31A & CGTGTCGGTCATGGCGGAACTGGAAGCC & CGGCTTCCAGTTCCGCCATGACCGACAC \\
& G & G \\
\hline EncFtn-E34A & CATGGAGGAACTGGCAGCCGTCGATTGG & GTACCAATCGACGGCTGCCAGTTCCTCC \\
& TAC & ATG \\
\hline EncFtn-W38A & GCCGTCGATGCGTACGACCAGCGCGTCG & CGACGCGCTGGTCGTACGCATCGACGGC \\
\hline EncFtn-W38G & CTGGAAGCCGTCGATGGGTACGACCAGC & CGCGCTGGTCGTACCCATCGACGGCTTC \\
& GCG & CAG \\
\hline EncFtn-E31A/E34A & CGGTCATGGCGGAACTGGCAGCCGTCGA & CCAATCGACGGCTGCCAGTTCCGCCATG \\
& TTGG & ACCG \\
\hline
\end{tabular}

1089 Site-directed mutagenesis (SDM) primers. pACYCDuet-1-EncFtn (He et al., 2016) was used to produce

1090 single mutants where pACYCDuet-1-EncFtn-E31A was used for EncFtn-E31A/E34A double mutant. All 1091 primers were purchased from IDT. 
1092 Table S9. Constructs used in this study.

\begin{tabular}{|c|c|c|c|c|c|}
\hline Construct & Sequence & Amino acids & $\begin{array}{l}\text { Average } \\
\text { Molecular } \\
\text { weight (Da) }\end{array}$ & pl & $\begin{array}{l}\text { Extinction } \\
\text { coefficient } \\
\left(\mathrm{M}^{-1} \mathrm{~cm}^{-1}\right)\end{array}$ \\
\hline EncFtn & $\begin{array}{l}\text { MAQSSNSTHEPLEVLKEETVNRHRAIVSVMEELEAVDWYDQRVDAS } \\
\text { TDPELTAILAHNRDEEKEHAAMTLEWLRRNDAKWAEHLRTYLFTEG } \\
\text { PITAIEAADTAGEGSGGDAAKGATAQGDGSLGIGSLKGEAALARPPRL }\end{array}$ & 140 & 15192.74 & 4.75 & 19480 \\
\hline $\begin{array}{l}\text { EncFtn- } \\
\text { E31A }\end{array}$ & $\begin{array}{l}\text { MAQSSNSTHEPLEVLKEETVNRHRAIVSVMAELEAVDWYDQRVDAS } \\
\text { TDPELTAILAHNRDEEKEHAAMTLEWLRRNDAKWAEHLRTYLFTEG } \\
\text { PITAIEAADTAGEGSGGDAAKGATAQGDGSLGIGSLKGEAALARPPRL }\end{array}$ & 140 & 15134.71 & 4.80 & 19480 \\
\hline $\begin{array}{l}\text { EncFtn- } \\
\text { E34A }\end{array}$ & $\begin{array}{l}\text { MAQSSNSTHEPLEVLKEETVNRHRAIVSVMEELAAVDWYDQRVDAS } \\
\text { TDPELTAILAHNRDEEKEHAAMTLEWLRRNDAKW̄AEHLRTYLFTEG } \\
\text { PITAIEAADTAGEGSGGDAAKGATAQGDGSLGIGSLKGEAALARPPRL }\end{array}$ & 140 & 15134.71 & 4.80 & 19480 \\
\hline $\begin{array}{l}\text { EncFtn- } \\
\text { W38A }\end{array}$ & $\begin{array}{l}\text { MAQSSNSTHEPLEVLKEETVNRHRAIVSVMEELEAVDAYDQRVDAS } \\
\text { TDPELTAILAHNRDEEKEHAAMTLEWLRRNDAKWAEHLRTYLFTEG } \\
\text { PITAIEAADTAGEGSGGDAAKGATAQGDGSLGIGSLKGEAALARPPRL }\end{array}$ & 140 & 15077.61 & 4.75 & 13980 \\
\hline $\begin{array}{l}\text { EncFtn- } \\
\text { W38G }\end{array}$ & $\begin{array}{l}\text { MAQSSNSTHEPLEVLKEETVNRHRAIVSVMEELEAVDGYDQRVDAS } \\
\text { TDPELTAILAHNRDEEKEHAAMTLEWLRRNDAKWAEHLRTYLFTEG } \\
\text { PITAIEAADTAGEGSGGDAAKGATAQGDGSLGIGSLKGEAALARPPRL }\end{array}$ & 140 & 15063.58 & 4.75 & 13980 \\
\hline Enc & $\begin{array}{c}\text { MGNDLMRDLAPISAKAWAEIETEARGTLTVTLAARKVVDFKGPLGWDASSV } \\
\text { SLGRTEALAEEPKAAGSAAVVTVRKRAVQPLIELCVPFTLKRAELEAIARGAS } \\
\text { DADLDPVIEAARAIAIAEDRAVFHGFAAGGITGIGEASAEHALDLPADLADFP } \\
\text { GVLVRALAVLRDRGVDGPYALVLGRTVYQQLMETTTPGGYPVLQHVRRLFE } \\
\text { GPLIWAPGVDGAMLISQRGGDFELTVGRDFS IGYHDHDAQSVHLYLQESMT } \\
\text { FRCLGPEAAVPLRGLSQAATKA }\end{array}$ & 281 & 29790.04 & 5.21 & 23950 \\
\hline ID-EncFtn & $\begin{array}{c}\text { MAQSSNSTHEPLEVLKEETVNRHRAIVSVMEELEAVDW } \\
\text { YDQRVDASTDPELTAILAHNRDEEKEHAAMTLEWLRRN } \\
\text { DAKWAEHLRTYLFTEGPITAIRSWSHPQFEK }\end{array}$ & 107 & 12534.15 & 5.04 & 24980 \\
\hline
\end{tabular}


1094 Table 10. Crystallization conditions for EncFtn-sH variants.

\begin{tabular}{|c|c|c|c|c|}
\hline Variant & $\begin{array}{l}\text { X-ray diffraction } \\
\text { resolution }\end{array}$ & Space group & Crystallization conditions & Cryo-protectant \\
\hline $\begin{array}{l}\text { EncFtn- } \\
\text { E31A }\end{array}$ & $2.75 \AA$ & $P 12,1$ & $\begin{array}{l}\text { 15\% (w/v) PEG } 3350+0.15 \\
\text { M Calcium Acetate }\end{array}$ & $\begin{array}{l}15 \%(\mathrm{w} / \mathrm{v}) \text { PEG } 3350 \\
+0.15 \mathrm{M} \text { Calcium } \\
\text { Acetate }+20 \%(\mathrm{v} / \mathrm{v}) \\
\text { PEG } 200\end{array}$ \\
\hline $\begin{array}{l}\text { EncFtn- } \\
\text { E34A }\end{array}$ & $2.19 \AA$ & $P 12,1$ & $\begin{array}{l}\text { 14\% (w/v) PEG } 3350+0.15 \\
\text { M Calcium Acetate }\end{array}$ & $\begin{array}{l}15 \%(\mathrm{w} / \mathrm{v}) \text { PEG } 3350 \\
+0.14 \mathrm{M} \text { Calcium } \\
\text { Acetate }+20 \%(\mathrm{v} / \mathrm{v}) \\
\text { PEG } 200+50 \mathrm{mM} \\
\text { Tris- } \mathrm{HCl}(\mathrm{pH} 8.5)+1 \\
\mathrm{mM} \mathrm{acidic} \mathrm{FeSO}_{4}\end{array}$ \\
\hline
\end{tabular}

1095 The crystallization solutions were diluted from stock solutions prepared as follows: 50\% (w/v) PEG 3350, $1096100 \%$ (v/v) PEG 200, $1 \mathrm{M}$ calcium acetate, $1 \mathrm{M}$ magnesium formate, $1 \mathrm{M}$ Tris- $\mathrm{HCl}$ (pH 8.5). 100 mM FeSO 1097 was freshly dissolved in $0.1 \%$ (v/v) $\mathrm{HCl}$ before diluting in the cryo-protectant solutions.

1098 
Table 11. Data collection and refinement statistics.

\begin{tabular}{|c|c|c|}
\hline & $E 31 A^{*}$ & $E 34 A^{*}$ \\
\hline \multicolumn{3}{|l|}{ Data collection } \\
\hline Wavelength & 1.74 & 1.74 \\
\hline Resolution range & $\begin{array}{l}49.40-2.66 \\
(2.75-2.66)\end{array}$ & $\begin{array}{l}48.73-2.19 \\
(2.27-2.19)\end{array}$ \\
\hline Space group & $\mathrm{P} 1211$ & $\mathrm{P} 122_{1} 1$ \\
\hline $\begin{array}{l}\text { Unit cell }(\ddot{A}) a \\
b \\
c\end{array}$ & $\begin{array}{l}97.89 \\
120.16 \\
139.37\end{array}$ & $\begin{array}{l}97.79 \\
120.14 \\
139.34\end{array}$ \\
\hline$\beta\left(^{\circ}\right)$ & 95.33 & 95.20 \\
\hline Total reflections & $310,119(30,187)$ & $906,663(86,277)$ \\
\hline Unique reflections & $170,103(16,471)$ & $31,4834(30,221)$ \\
\hline Multiplicity & $1.8(1.8)$ & $2.9(2.9)$ \\
\hline Completeness (\%) & $93.30(90.35)$ & 96.37 (92.66) \\
\hline Mean I/sigma(I) & $5.45(1.40)$ & $8.04(1.43)$ \\
\hline Wilson B-factor $\left(\AA^{2}\right)$ & 39.14 & 33.05 \\
\hline$R_{\text {merge }}$ & $0.136(0.657)$ & $0.094(0.688)$ \\
\hline$R_{\text {meas }}$ & $0.184(0.878)$ & $0.116(0.842)$ \\
\hline $\mathrm{R}_{\text {pim }}$ & $0.123(0.578)$ & $0.065(0.478)$ \\
\hline $\mathrm{CC}_{1 / 2}$ & $0.978(0.517)$ & $0.995(0.579)$ \\
\hline $\mathrm{CC}^{*}$ & $0.994(0.826)$ & $0.999(0.857)$ \\
\hline \multicolumn{3}{|l|}{ Refinement } \\
\hline $\begin{array}{l}\text { Reflections used in } \\
\text { refinement }\end{array}$ & $170,031(16,463)$ & $314,739(30,212)$ \\
\hline $\begin{array}{l}\text { Reflections used for } \\
\mathrm{R}_{\text {free }}\end{array}$ & $8,346(794)$ & $15,590(1548)$ \\
\hline $\mathrm{R}_{\text {work }}$ & $0.195(0.297)$ & $0.184(0.282)$ \\
\hline $\mathrm{R}_{\text {free }}$ & $0.236(0.327)$ & $0.212(0.315)$ \\
\hline $\mathrm{CC}_{\text {work }}$ & $0.946(0.748)$ & $0.959(0.768)$ \\
\hline $\mathrm{CC}_{\text {free }}$ & $0.914(0.684)$ & $0.952(0.689)$ \\
\hline \multicolumn{3}{|l|}{ Model } \\
\hline $\begin{array}{l}\text { Number of non- } \\
\text { hydrogen atoms }\end{array}$ & 22,382 & 22,760 \\
\hline macromolecules & 21,988 & 22,072 \\
\hline ligands & 65 & 48 \\
\hline solvent & 329 & 640 \\
\hline Protein residues & 2680 & 2696 \\
\hline RMS(bonds) (Ä) & 0.007 & 0.005 \\
\hline RMS(angles) $\left({ }^{\circ}\right.$ ) & 1.03 & 0.87 \\
\hline \multicolumn{3}{|l|}{ Ramachandran } \\
\hline favored (\%) & 99.69 & 99.77 \\
\hline allowed (\%) & 0.31 & 0.23 \\
\hline outliers (\%) & 0.00 & 0.00 \\
\hline Rotamer outliers (\%) & 0.26 & 1.07 \\
\hline Clashscore & 4.79 & 3.01 \\
\hline Average B-factor $\left(\AA^{2}\right)$ & 41.64 & 40.53 \\
\hline macromolecules & 41.66 & 40.52 \\
\hline ligands & 55.57 & 46.17 \\
\hline solvent & 37.08 & 40.62 \\
\hline PDB ID & 6SUW & $6 S V 1$ \\
\hline
\end{tabular}

1100 Statistics for the highest-resolution shell are shown in parentheses. *Friedel pairs are treated as

1101 separate reflections for data analysis and refinement. 
The authors declare that no competing interests exist.

1105

1106

1107

1108

1109

1110

1111

1112

1113

1114

1115

1116

1117

1118

1119

1120

1121

1122

1123

1124

1125

1126

1127

1128

1129

1130

1131

1132

1133

1134

1135

1136

1137

1138

1139

1140

1141

1142

1143

1144

1145

1146

1147

1148

1149

1150

1151

1152

1153

\section{Author contributions}

CP, Conception and design, Acquisition of data, Analysis and interpretation of data, Drafting or revising the article.

JR, Conception and design, Acquisition of data, Analysis and interpretation of data. Drafting or revising the article.

DH, Conception and design, Acquisition of data, Analysis and interpretation of data.

KJG, ID-MS methods development and acquisition of data, Analysis and interpretation of data

WAS, Acquisition of data.

LA, Acquisition of data.

CLM, Acquisition of data.

KJW, Acquisition of data, Interpretation of data.

DJC, Conception and design, Acquisition of data, Analysis and interpretation of data, Drafting or revising the article.

JMW, Conception and design, Acquisition of data, Analysis and interpretation of data, Drafting or revising the article.

\section{Funding}

This work was supported a Royal Society Research Grant awarded to JMW [RG130585] and a BBSRC New Investigator Grant to JMW and DJC [BB/N005570/1]. CP and WAS are funded by the BBSRC New Investigator Grant [BB/N005570/1]. JMW is funded by Newcastle University. DJC and JR are funded by the University of Edinburgh. JR is funded by a BBSRC EastBio DTP studentship [BB/M010996/1]. DH was funded by the China Scholarship Council. KJW was funded by the Wellcome Trust and Royal Society through a Sir Henry Dale Fellowship awarded to KJW [098375/Z/12/Z]. Equipment for Transmission Electron Microscopy was funded through the BBSRC 17ALERT call [BB/R013942/1]. FT-ICR instrumentation was funded by BBSRC 17ALERT [BB/R013993/1].

\footnotetext{
Abbreviations

Enc, encapsulin; EncFtn, encapsulated ferritin; FOC, ferroxidase center; MS, mass spectrometry; nESI, Native nanoelectrospray ionization; CIU, collision induced unfolding; FT-ICR, Fouriertransform ion cyclotron resonance; ID, isotope depletion.

\section{Acknowledgements}

We would like to thank staff at the Newcastle University Electron Microscopy Research Services for assistance with TEM. We would like to thank Diamond Light Source for beamtime (proposal

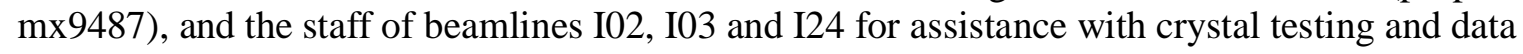
collection. We would like to thank Dr Arnaud Baslé, Prof. Dominic Campopiano and Gregor Skeldon for their constructive advice throughout this project.
} 
Figure Supplements

\begin{tabular}{|c|c|}
\hline Primary Figure & Associated Supplementary Figure(s) \\
\hline \multirow{3}{*}{$\begin{array}{l}\text { Figure 3. Purification of recombinant EncFtn and } \\
\text { Enc:EncFtn protein complexes. }\end{array}$} & $\begin{array}{l}\text { Figure 3-figure supplement } 1 . \\
\text { SDS-PAGE of Enc:EncFtn proteins. }\end{array}$ \\
\hline & $\begin{array}{c}\text { Figure 3-figure supplement } 2 \text {. } \\
\text { Transmission electron micrographs of Enc:EncFtn } \\
\text { complexes. Figure 3-figure supplement } 2 \text {. }\end{array}$ \\
\hline & $\begin{array}{c}\text { Figure 3-figure supplement } 3 \text {. } \\
\text { Comparison between W38G and W38A data in } \\
\text { encapsulated ferritins. }\end{array}$ \\
\hline \multirow{2}{*}{$\begin{array}{l}\text { Figure 4. Comparison of metal ion binding in } \\
\text { EncFtn entry site variants. }\end{array}$} & $\begin{array}{l}\text { Figure 4-figure supplement } 1 . \\
\text { EncFtn-E31A entry site electron density map. }\end{array}$ \\
\hline & $\begin{array}{l}\text { Figure 4-figure supplement } 2 . \\
\text { EncFtn-E34A entry site electron density map. }\end{array}$ \\
\hline \multirow{3}{*}{ Figure 5. Native MS Analysis of EncFtn variants. } & $\begin{array}{l}\text { Figure 5-figure supplement } 1 . \\
\text { Native MS Dissociation of EncFtn variants. }\end{array}$ \\
\hline & $\begin{array}{l}\text { Figure 5-figure supplement } 2 \text {. } \\
\text { Collision Induced unfolding (CIU) of the EncFtn } \\
\text { variants determined by ion mobility mass } \\
\text { spectrometry. }\end{array}$ \\
\hline & $\begin{array}{c}\text { Figure 5-figure supplement } 3 \text {. } \\
\text { Extracted ion mobility drift time distributions of } \\
\text { EncFtn variants at } 10 \mathrm{~V} \text { collision voltage from CIU } \\
\text { experiments. }\end{array}$ \\
\hline \multirow{3}{*}{$\begin{array}{l}\text { Figure 6. Ferroxidase activity of EncFtn and } \\
\text { Enc:EncFtn complexes. }\end{array}$} & $\begin{array}{l}\text { Figure 6-figure supplement } 1 . \\
\text { Ferroxidase activity of EncFtn and Enc:EncFtn } \\
\text { encapsulated ferritins. }\end{array}$ \\
\hline & $\begin{array}{l}\text { Figure 6-figure supplement } 2 \text {. } \\
\text { Linear Regression on first 200s of ferroxidase } \\
\text { assays with EncFtn and Enc:EncFtn complexes. }\end{array}$ \\
\hline & $\begin{array}{l}\text { Figure 6-figure supplement } 3 . \\
\text { Comparison of ferroxidase activities of EncFtn- } \\
\text { E34A and EncFtn-E31A/E34A. }\end{array}$ \\
\hline \multirow{2}{*}{$\begin{array}{l}\text { Figure 8. Intrinsic fluorescence of EncFtn wild-type } \\
\text { and variants titrated with } \mathrm{Zn}(\mathrm{II}) \text {. }\end{array}$} & $\begin{array}{l}\text { Figure 8-figure supplement } 1 . \\
\text { Normalized Tryptophan fluorescence emission } \\
\text { spectra of EncFtn variants. }\end{array}$ \\
\hline & $\begin{array}{c}\text { Figure 8-figure supplement } 2 \text {. } \\
\text { Normalized Tryptophan fluorescence emission } \\
\text { spectra of EncFtn variants in the presence or } \\
\text { absence of } \mathrm{Zn}(\mathrm{II}) \text {. }\end{array}$ \\
\hline \multirow{5}{*}{$\begin{array}{l}\text { Figure 9. Native FT-ICR mass spectrum of } I D- \\
\text { EncFtn }\end{array}$} & $\begin{array}{c}\text { Figure 9-figure supplement } 1 . \\
I D \text {-EncFtn monomer with theoretical } \mathrm{m} / \mathrm{z} \text { value. }\end{array}$ \\
\hline & $\begin{array}{c}\text { Figure 9-figure supplement } 2 \text {. } \\
\text { Metal association of } 23+\text { decamer charge state of } \\
\text { ID-EncFtn }\end{array}$ \\
\hline & $\begin{array}{c}\text { Figure 9-figure supplement } 3 \text {. } \\
\text { Dissociation pathway of } I D \text {-EncFtn loaded with } \\
\text { iron }\end{array}$ \\
\hline & $\begin{array}{l}\text { Figure 9-figure supplement 4. Dissociation } \\
\text { pathway of } I D \text {-EncFtn loaded with zinc }\end{array}$ \\
\hline & $\begin{array}{l}\text { Figure 9-figure supplement 5. Dissociation } \\
\text { pathway of } I D \text {-EncFtn loaded with iron and zinc }\end{array}$ \\
\hline
\end{tabular}

